\title{
Segmental mandibular bone reconstruction with a carbonate-substituted hydroxyapatite-coated modular endoprosthetic poly(e-caprolactone) scaffold in Macaca fascicularis
}

\author{
Nattharee Chanchareonsook, ${ }^{1}$ Henk Tideman, ${ }^{2}$ Stephen E. Feinberg, ${ }^{3,4}$ \\ Leenaporn Jongpaiboonkit, ${ }^{5}$ Shermin Lee, ${ }^{1}$ Colleen Flanagan, ${ }^{4}$ Gita Krishnaswamy, ${ }^{6}$ John Jansen ${ }^{7}$ \\ ${ }^{1}$ Department of Oral and Maxillofacial Surgery, National Dental Centre, Singapore, Singapore \\ ${ }^{2}$ Department of Oral and Maxillofacial Surgery, Research advisor, National Dental Centre, Singapore, Singapore \\ ${ }^{3}$ Department of Oral and Maxillofacial Surgery, University of Michigan, Ann Arbor, Michigan \\ ${ }^{4}$ Department of Biomedical Engineering, College of Engineering, University of Michigan, Ann Arbor, Michigan \\ ${ }^{5}$ Tissue Regeneration Systems, Inc, Ann Arbor, Michigan \\ ${ }^{6}$ Centre for Quantitative Medicine, Duke-NUS Graduate Medical School, Singapore, Singapore \\ ${ }^{7}$ Department of Biomaterials, Radboud University Nijmegen Medical Centre, Nijmegen, The Netherlands
}

Received 18 July 2013; revised 3 October 2013; accepted 12 October 2013

Published online 21 November 2013 in Wiley Online Library (wileyonlinelibrary.com). DOI: 10.1002/jbm.b.33077

\begin{abstract}
A bio-degradable scaffold incorporating osteoinductive factors is one of the alternative methods for achieving the regeneration of a mandibular bone defect. The current pilot study addressed such a bone reconstruction in a non-human primate model, Macaca fascicularis monkeys, with an engineered poly( $\varepsilon$-caprolactone) (PCL) scaffold, provided with a carbonate-substituted hydroxyapatite coating. The scaffolds were implanted into unilaterally created mandibular segmental defects in 24 monkeys. Three experimental groups were formed: (1) scaffolds with rhBMP-2 $(n=8),(2)$ scaffolds with autologous mixed bone marrow cells $(n=8)$, and (3) empty scaffolds as a control group $(n=8)$. Evaluation was based on clinical observation as well as micro-CT, mechanical, and his-
\end{abstract}

tological analyses. Despite a high infection rate, the overall results showed that the currently designed PCL scaffolds had insufficient load-bearing capability, and complete bone union was not achieved after 6 months of implantation. Nevertheless, the group of PCL scaffolds loaded with rhBMP-2 showed evidence of bone-regenerative potential, in contrast to PCL with autologous mixed bone marrow cells and the control group. (C) 2013 Wiley Periodicals, Inc. J Biomed Mater Res Part B: Appl Biomater, 102B: 962-976, 2014.

Key Words: poly( $\varepsilon$-caprolactone), carbonate-substituted hydroxyapatite, mandible, tissue engineering, scaffold, bone morphogenic protein-2, bone marrow cells

How to cite this article: Chanchareonsook N, Tideman H, Feinberg SE, Jongpaiboonkit L, Lee S, Flanagan C, Krishnaswamy G, Jansen J. 2014. Segmental mandibular bone reconstruction with a carbonate-substituted hydroxyapatite-coated modular endoprosthetic poly( $\varepsilon$-caprolactone) scaffold in Macaca fascicularis. J Biomed Mater Res Part B 2014:102B:962-976.

\section{INTRODUCTION}

Mandibular bone provides the skeletal base for teeth, which play a critical role in mastication, speech, and maintenance of the facial profile. ${ }^{1}$ Reconstruction of large mandibular defects caused by trauma, tumor resection, and congenital defects is a significant clinical challenge. ${ }^{2}$ Various methods of mandibular defect reconstruction have been reported in several surgical techniques involving reconstruction plate, free bone graft, pedicle bone graft, particulate bone cancellous marrow graft, microvascular free flap, transport distraction osteogenesis, modular endoprosthesis, and tissue engineering. Each technique has its own benefits and limitations. The current "gold standard" treatment is either an autogenous free bone graft or a vascularized microvascular free fibular flap. ${ }^{1}$ However, even this standard has limita- tions in terms of aesthetic and functional outcomes when the bone graft does not replicate the original complex mandibular geometry. The procedure is also time-consuming, including a hospital stay, and is associated with significant donor-site morbidity. These problems have led clinicians to explore alternative procedures for mandibular reconstruction.

In 2006, Lee et al. ${ }^{3}$ introduced a modular endoprosthesis for mandibular reconstruction. This device was made of titanium alloy, and the prosthesis stems were cemented into the remaining bone stumps on either side of the mandibular defect. The experimental animal study with this approach showed an abundance of bone formation around the body of the modular endoprosthesis at 6 months post-surgery; however, the soft-tissue healing was not ideal, resulting in dehiscence and, in some cases, hardware exposure. In 
addition, hardware failure (i.e., several screws of the modular endoprosthesis becoming loose) was found. ${ }^{3-5}$

A recently introduced alternative direction for mandibular bone reconstruction involves tissue-engineering techniques, which offer potential advantages such as the absence of donor-site morbidity and an ability to regenerate original bone geometry. Based on the results of the earlier study with the titanium modular endoprosthesis, we decided to pursue such a tissue-engineering approach and designed a biodegradable osteoinductive modular endoprosthetic scaffold for the regeneration of a segmental mandibular defect.

Poly( $\varepsilon$-caprolactone) (PCL) was selected for the manufacture of the endoprosthesis. PCL is a bioresorbable polymer with potential applications for bone and cartilage repair and has several advantages over other polymers. PCL is more stable in ambient conditions, is readily available in large quantities, and can be easily combined as well as processed with other materials to further formulate the tissue response. ${ }^{6,7}$ PCL scaffolds can be fabricated by selective laser sintering (SLS), a rapid prototyping/solid free-form fabrication (SFF) technique to fit complex anatomic locations. This technology allows for the design of a scaffold with computationally predicted properties and a possible global anatomic architecture that matches the original bone defect and supports the in-growth of bone tissue. ${ }^{8,9}$ The selected percentages of scaffold porosity, structure, and mechanical design can be controlled. Porosity between 37 and $55 \%$ has been reported to possess mechanical properties comparable with those of human trabecular bone, and the compressive modulus of such a scaffold was found to be within the 52-68-MPa range, with ultimate compressive strength within the 2.0-3.2-MPa range. ${ }^{9}$ This makes such a manufactured material an attractive substitute for human bone and enhances its application for bone regeneration.

Osteoinductive or autoinductive bone formation is a mechanism of cellular differentiation towards bone of one tissue due to the physicochemical effect or contact with another tissue. ${ }^{10}$ It generally can only be induced by heterotopic implantation of demineralized bone matrix (DBM) or BMPs into a region where bone does not naturally grow. ${ }^{11}$ PCL is not osteoinductive, which limits its applications in the regeneration of critical-sized bone defects. To enhance the bone-regenerative properties, PCL scaffolds containing growth factors, and in conjunction with a carbonatesubstituted hydroxyapatite coating, have been shown to be promising in creating osteoinductive scaffolds. In 2011, Suárez-González et al. reported mineral coatings on polycaprolactone scaffolds serving as templates for growth-factor binding and release. ${ }^{12}$ Mineral coatings were formed by a biomimetic approach that consisted of the incubation of scaffolds in modified simulated body fluids (mSBF) with a composition similar to that of human plasma, but with double the concentrations of calcium and phosphate. Such scaffolds demonstrated the ability of attachment and sustained release of growth factors, such as VEGF and BMP-2, which were dependent on the solubility of the mineral coating. ${ }^{12,13}$

In addition to growth factors such as rhBMP-2 ${ }^{14-18}$ and rhBMP-7, ${ }^{14,19-21}$ bone marrow stromal cells (BMSCs) have been found to be a stimulus for bone regeneration, being capable of differentiation into mesenchymal tissues such as bone and cartilage. ${ }^{22-26}$ BMSCs or cultivated osteoprogenitor cells can be seeded into a porous scaffold, and, when given the appropriate environmental signals, can be directed down the osteogenic lineage and cued to form bone tissue. ${ }^{27}$ BMSCs are readily available and can be isolated from bone marrow or fat tissue. Numerous successful animal studies have been reported, where mandibular continuity defects were regenerated on a scaffold provided with bone marrow stromal cells. ${ }^{26,28-30}$

In view of the above, the aim of this study was to regenerate a segmental mandibular bone defect by means of a 3D designed PCL scaffold provided with a carbonatesubstituted hydroxyapatite (CHA) coating for the delivery of osteoinductive factors to the defect site. The study compared the use of empty PCL scaffolds (PCL-control), PCL scaffolds seeded with autologous bone marrow cells in a bovine collagen type I gel (PCL-CELL), and PCL scaffolds provided with additional rhBMP-2 (PCL-BMP). We hypothesized that the osteoinductive scaffold loaded with rhBMP-2 or bone marrow cells could achieve bone union and overlying soft-tissue healing with sufficient load-bearing capacity within 6 months after its installation into the mandibular segmental defect in a non-human primate model.

\section{MATERIALS AND METHODS}

\section{Animals}

Twenty-four healthy, adult male Macaca fascicularis monkeys, with an average weight of 6-7 $\mathrm{kg}$, were used in this study. The experimental protocol was approved by the Institutional Animal Care and Use Committee of SingHealth in Singapore. Animal surgery was performed at the SingHealth Experimental Animal Centre (SEMC), Singapore. The animal laboratory has been certified by the International Association for the Assessment of Laboratory Animal Care (IACUC), Singapore.

\section{PCL scaffolds and calcium phosphate coating}

Poly- $\varepsilon$-caprolactone (PCL) powder (CAPA 6501, Solvay Caprolactones, Warrington, Cheshire, UK) was used to fabricate the PCL scaffolds. This particular form of PCL has a melting point of $60^{\circ} \mathrm{C}$, a molecular weight of $50,000 \mathrm{kDa}$, and particle size distribution in the $10-100-\mu \mathrm{m}$ range.

Fabrication of PCL scaffolds. The PCL scaffolds were fabricated by the Department of Biomedical Engineering, University of Michigan, Ann Arbor. For the fabrication process, computed tomographic (CT) scans of dry monkey mandibles were made, and scaffolds were fabricated via laser sintering as previously reported. ${ }^{9}$ With the CT images as a guide, mandibular scaffolds were created with a controlled architecture. The design was then exported to a Sinterstation $2000^{\mathrm{TM}}$ machine (3D Systems, Valencia, CA) in STL file format and used to construct scaffolds layer-by-layer, with a powder layer, by the selective laser sintering (SLS) processing. The body of the implant was 15-mm long and 12-mm high and possessed a 3D orthogonal periodic porous 

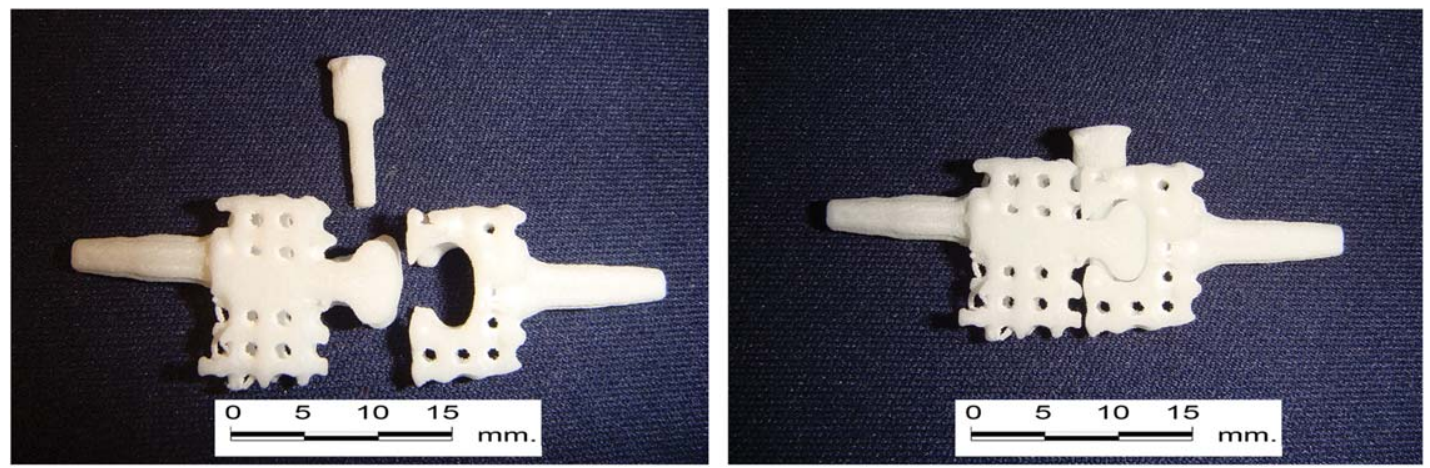

FIGURE 1. PCL polymer endoprosthetic mandibular scaffold has anterior and posterior parts with a "dovetail" inter-lock design. A scaffold pin is used to stabilize the two parts. Anterior and posterior endoprosthetic stems are designed to fit into the prepared cavity in the cancellous bone of native mandibular segments. The surface of scaffold is coated with CHA. [Color figure can be viewed in the online issue, which is available at wileyonlinelibrary.com.]

architecture. The body of the implant was also modular, comprised of anterior and posterior components, which were fixed together with a special lock-on design. Mechanical analysis confirmed that the "dovetail joint" between the two components was failing (fracture point) at $30 \mathrm{~N}$. The stems were $12-\mathrm{mm}$ long, 4-mm high, and $2.5 \mathrm{~mm}$ in diameter and were made to fit the marrow space of the mandible as closely as possible. In cross-section, the stems showed a star-shaped appearance, to increase the bone-scaffold contact area. Micro-CT analysis reviewed that the PCL scaffolds had a reasonably homogenous structure, with total surface area of $2089 \mathrm{~mm}^{2}$, porosity $75 \%$, and pore size of $1200 \mu \mathrm{m}$. All pores are interconnected (Figure 1).

PCL scaffolds with CHA coating. The PCL scaffolds were used as-received or provided with a CHA coating. The scaffold components were incubated in a modified simulated body fluid (mSBF) for 8 days at $37^{\circ} \mathrm{C}$ under continuous rotation. Prior to mSBF incubation, the PCL components were hydrolyzed in $1 \mathrm{M} \mathrm{NaOH}$ for $60 \mathrm{~min}$. After hydrolysis, plates were rinsed and incubated in the mSBF. The mSBF solution had a composition similar to that of human plasma, but with double the concentrations of calcium and phosphate to enhance mineral growth, and was prepared as previously reported ${ }^{9,13}$ : briefly, $141 \mathrm{mM} \mathrm{NaCl}, 4.0 \mathrm{mM} \mathrm{KCl}, 0.5$ $\mathrm{mM} \mathrm{MgSO}_{4}, 1.0 \mathrm{mM} \mathrm{MgCl}$, $4.2 \mathrm{mM} \mathrm{NaHCO}, 5.0 \mathrm{mM} \mathrm{CaCl}_{2}$, and $2.0 \mathrm{mM} \mathrm{KH}_{2} \mathrm{PO}_{4}$ in deionized ultra-filtered water, with $\mathrm{pH}$ adjusted to 6.8 with $2 \mathrm{~N} \mathrm{HCl}$ or $2 \mathrm{~N} \mathrm{NaOH}$. Before use in the animal study, all scaffolds (non-coated and CHA-coated) were sterilized by ethylene oxide gas.

\section{Bone morphogenic protein}

Recombinant human Bone Morphogenic Protein-2 (rhBMP2) in white freeze-dried powder form (GenScript, Piscataway, NJ) was used. RhBMP-2 solution was prepared according to the manufacturer's instructions, that is, 0.75 $\mathrm{mL}$ of $20 \mathrm{mmol}$ of acetic acid was gently dripped directly onto $1 \mathrm{mg}$ rh-BMP2, and $0.75 \mathrm{~mL}$ of sterile $1 \times$ PBS was added. Then, this solution was gently dripped onto and absorbed by the PCL scaffolds. Subsequently, scaffolds were incubated in a continuously shaking machine at $250 \mathrm{rpm}$.
The scaffolds were turned over at $7.5 \mathrm{~min}$, and shaking continued for an additional $7.5 \mathrm{~min}$. This preparation was performed under sterile conditions in the operating room, while the mandibular segmental operation was performed in each individual monkey.

Preparation of monkey autologous bone marrow cells in collagen gel

After the monkeys were anesthetized, a 3-mL quantity of bone marrow was aspirated from the trochanter bone from each monkey. The aspirate was processed with red blood cell lysis and cell counting under sterile conditions.

Ultrapure Bovine Collagen Solution (Sigma-Aldrich ${ }^{\circledR}$ C4243, St. Louis, MO) was used as a carrier for bone marrow cell-seeding. Collagen gel was prepared by the pipetting of $0.8 \mathrm{~mL}$ of $3 \mathrm{mg} / \mathrm{mL}$ Ultrapure Bovine Collagen Solution into an Eppendorf tube. Subsequently, $0.1 \mathrm{~mL}$ of $10 \times$ PBS was added to the solution, followed by gentle mixing with $75 \mu \mathrm{L} 0.1 \mathrm{M} \mathrm{NaOH}$. The $\mathrm{pH}$ of the solution was kept in the range of $\mathrm{pH} 7-8$. Then, a $125-\mu \mathrm{L}$ quantity of bone marrow cells (equivalent to $5 \times 10^{6}$ cells) was mixed with $475 \mu \mathrm{L}$ (pH-adjusted for appropriate gelling conditions) collagen solution. Bone marrow cells in collagen gel were incubated at $37^{\circ} \mathrm{C}$, in a humidified atmosphere of $95 \% \mathrm{O}_{2}$ and $5 \%$ $\mathrm{CO}_{2}$, for $40-45 \mathrm{~min}$.

Analysis of preliminary data from a pilot study confirmed that the collagen solution evoked no inflammatory or allergic reaction in the monkeys and proved that the viability of the marrow cells was maintained in the prepared collagen gel (data not shown).

Autologous bone marrow cells in $0.6 \mathrm{~mL}$ of collagen gel were transferred into the porous PCL scaffold and placed in an incubator. After $15 \mathrm{~min}$, the outer surface of the cellseeded scaffold was coated with an additional $0.4 \mathrm{~mL}$ of collagen gel. The construct was re-incubated for another 30 min before placement into the mandibular defect site.

\section{Surgical procedure}

The monkeys were fasted overnight and received $0.05 \mathrm{mg} /$ $\mathrm{kg}$ of intravenous atropine and $10 \mathrm{mg} / \mathrm{kg}$ of Ketamine (Parnell Laboratories, Alexandria, Australia) pre-operatively. All 

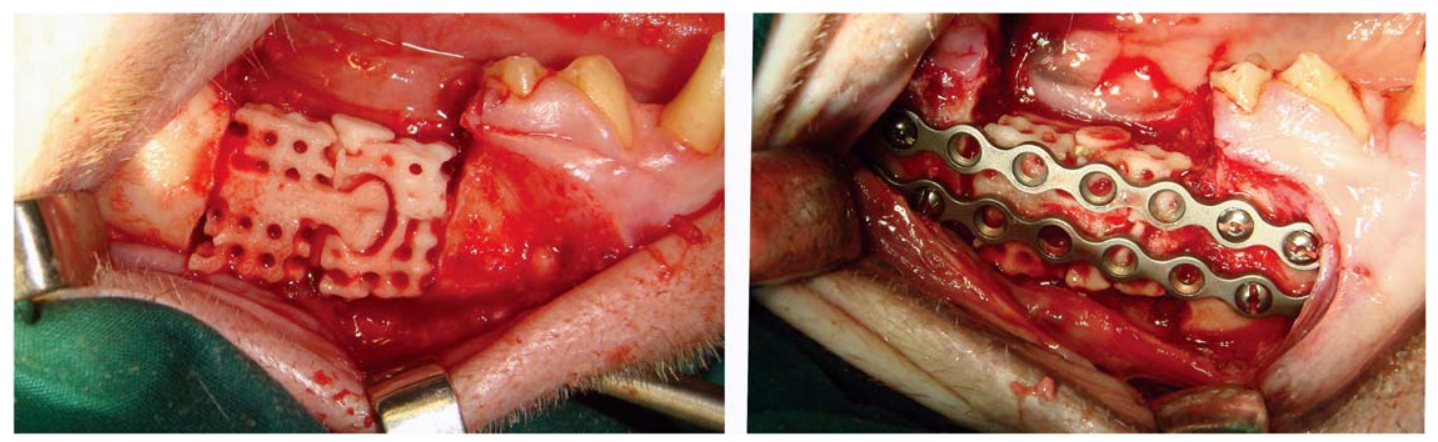

FIGURE 2. Clinical images of segmental mandibular reconstruction with PCL Endoprosthesis. The mandibular segment is stabilized by two titanium mini-plates and -screws. [Color figure can be viewed in the online issue, which is available at wileyonlinelibrary.com.]

animals were weighed prior to surgery. Induction and maintenance of anesthesia were performed with $2 \%$ isoflurane. Endotracheal intubation was performed with oral endotracheal tubes (gauge, $3.5 \mathrm{~mm}$ ). Intravenous analgesic $2 \mathrm{mg} / \mathrm{kg}$ carprofen (Rimadly ${ }^{\circledR}$ ) (Pfizer, NY) and antibiotics (ampicillin/cloxacillin) 6-8 $\mathrm{mg} / \mathrm{kg}$ were administered. The surgical site was disinfected with $1 \%$ Cetrimide, followed by $0.05 \%$ chlorhexidine and povidone iodine, and sterile drapes were used. An incision was made intra-orally, beginning with two vertical incisions between the second bicuspid and the first molar as well as behind the second molar. A horizontal incision 2-3 mm below the attached gingiva was made to connect the two vertical incisions. The periosteum was reflected to expose the lower border of the mandible at the ostectomy sites. A tapered fissure bur was used to perform the resection, and the block was subsequently removed. A 15 -mm section of the segmental defect was taken from the right side of the mandible. Bleeding from the inferior alveolar artery and vein was easily controlled with diathermy when necessary.

Three experimental groups were created: (1) PCL scaffold with CHA surface coating and soaked with rhBMP-2 (PCL-BMP, $n=8$ ); (2) PCL scaffold with CHA surface coating and seeded with bone marrow cells (PCL-CELL, $n=8$ ); and (3) PCL scaffold with CHA surface coating, as a control group (PCL-control, $n=8$ ). Before installation of the scaffolds, the medullar space of the anterior and posterior bone stumps was prepared with a tapered drill $(2.3 \mathrm{~mm}$ in diameter) to a depth of $12 \mathrm{~mm}$, to conform to the dimensions of the stems of the PCL scaffolds. The stems of the anterior and posterior modules were then inserted into the prepared grooves and press-fitted, and the stability was checked. The anterior and posterior modules were then connected and stabilized with a vertical pin (Figure 2).

After insertion of the endoprosthesis, occlusion was evaluated. As intermaxillary fixation was not possible in this animal model, two $\mathrm{Ti}$ mini-plates with 5-mm Ti screws were fixed between mandibular stumps to immobilize the reconstruction site. The buccinator and mylohyoid muscles were dissected, mobilized, and sutured over the device by means of $4 / 0$ Vicryl $^{\circledR}$ (Ethicon, Somerville, NJ), followed by closure of the mucosa, thus creating a two-layer closure. After surgery, radiographs were taken with a Siemens Poly- mobil Plus machine set at $40 \mathrm{kV}$ for $2 \mathrm{~ms}$ at a distance of $70 \mathrm{~cm}$. During imaging, animals were positioned with their right mandibles adjacent to the plate.

The animals were maintained in individual cages. Soft diet was provided until sacrifice. Ampicillin/cloxacillin 6-8 $\mathrm{mg} / \mathrm{kg}$ IM was administered for 7 days post-surgery, and Ketorolac trometamol (Toradol) $15-30 \mathrm{mg} / \mathrm{kg}$ IM was given for 2-3 days post-surgery.

\section{Endoprosthesis retrieval}

All animals were weighed and sacrificed at 6 months postoperatively. Mandibular specimens from condyle to condyle, with the device in situ, were harvested. Surrounding soft tissue was removed except around the reconstructed site. Radiographic examination was performed at the same settings as used for the preliminary assessment.

In half of the animals of each group, mandibles were harvested fresh to be used for mechanical testing. A 3-mL quantity of pentobarbitone was injected into the cardiac chamber to euthanize the animals. All retrieved specimens were kept frozen at $-20^{\circ} \mathrm{C}$ until needed for analysis.

For the other half of the animals in each group, harvesting was done after perfusion fixation. A 16-gauge intravenous catheter was inserted into the left ventricle and used for circulation with $300-500 \mathrm{~mL}$ of Hartman's solution, followed by $750 \mathrm{~mL}$ of a mixture of $2.5 \%$ paraformaldehyde and $2 \%$ glutaraldehyde. The specimens were kept soaked in $10 \%$ glutaraldehyde.

\section{Micro-CT evaluation}

The specimens containing the reconstruction device were scanned in a GE eXplore Locus SP MicroCT scanner (GE Healthcare, Thermo Scientific, Waltham, MA), with a focal spot of $8 \mu \mathrm{m}$, pixel size of $18 \mu \mathrm{m}$, scanning configuration isotropic voxels of $8 \times 8 \times 8 \mu^{3}$ focal spot size, and isotropic resolutions at $8 \mu \mathrm{m}$.

Mini-plates and screws were removed before the scanning process, to avoid scattering due to the presence of metal. The area of scan was extended to the maximum diameter of the scan view and beyond the region of interest (ROI) and the reconstruction site, which included endpoints of the anterior and posterior scaffold stems. The digitized signals were then transferred to a computer for 


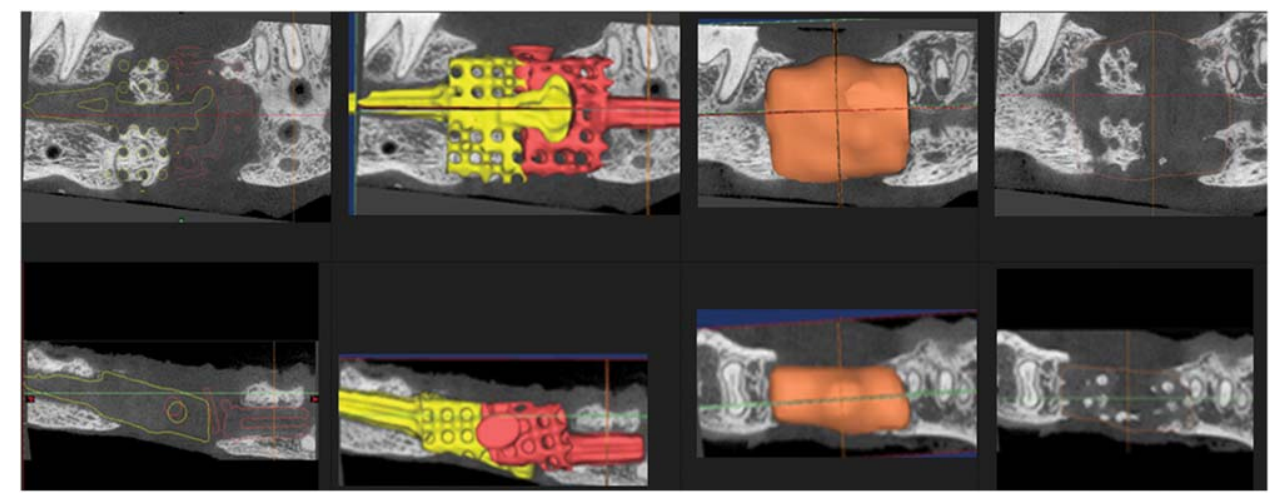

FIGURE 3. The ROI inside the scaffold was created along the boundary of the scaffold body with the Mimics $x 6414.0$ computer program. The

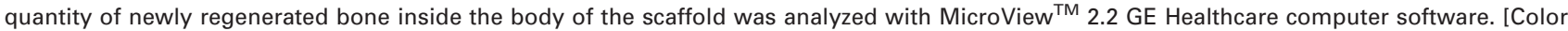
figure can be viewed in the online issue, which is available at wileyonlinelibrary.com.]

reconstruction of the micro-CT slices. Standardized calibration was used for comparison with bone, air, and water. All images were calibrated in Hounsfield units (HU) for quantitative analysis. The new bone analysis was analyzed with MicroView $^{\circledR} 2.2$ software (GE Healthcare, Waukesha, WI) and Mimics ${ }^{\circledR}$ Software (Mimics 14.01 64-bit, Materialise, Leuven, Belgium).

Micro-CT slices were reconstructed perpendicular to the long axis of the mandibular reconstruction. Bone union of the mandibular stem was evaluated. Bone volume (\%) at the reconstruction site was identified with Microview computer software. To investigate new bone formation inside the scaffold, we used the Stereo Lithography (STL) digital data of the scaffold to indicate the ROI as the boundary of the scaffold body, with Mimics ${ }^{\circledR}$ Software. The created ROI was transferred to the individual scan of the specimen in the MicroView ${ }^{\circledR}$ program. Bone volume (\%), tissue mineral density (TMD) value $(\mathrm{mg} / \mathrm{mL}$ ), and bone mineral density (BMD) $(\mathrm{mg} / \mathrm{mL})$ were then evaluated (Figure 3$)$.

\section{Mechanical testing examination}

The specimens for mechanical testing were processed at the Biomedical Engineering Laboratory, College of Engineering, The University of Michigan, Ann Arbor, MI. The three-point bending test was used to determine their stiffness in an MTS Alliance RT/30 Elite ${ }^{\mathrm{TM}}$ Controller testing machine (TestResources, Shakopee, MN). Each specimen was placed on the biomechanical three-point bending test fixture, with both condyles and the mid-anterior lingual bone surface placed on a custom-made jig (Figure 4). A force at a constant displacement rate of $25 \mathrm{~mm} / \mathrm{min}$ was applied to the lower border of the mandibular body. The load-displacement data were recorded at a frequency of $15 \mathrm{~Hz}$, for determination of the stiffness of the reconstructed mandibles without breaking the specimens.

A pilot study was conducted to determine the maximum load that could be applied without mandibular fracture. The data were acquired from two dry intact macaque mandibles. The first dry mandible was placed on the biomechanical three-point bending testing fixture as above. The vertical linear displacement was applied by vertical load on one side of the mandibular body. Once the pre-load was reached, data were acquired at a rate of $15 \mathrm{~Hz}$, while a load was applied at a displacement rate of $0.25 \mathrm{~mm} / \mathrm{min}$ until the failure load resulted in mandibular fracture at a loading force of $889.6 \mathrm{~N}$. The second dry mandibular specimen was tested similarly, except that the maximum load was reduced to $111.21 \mathrm{~N}$, or $12.5 \%$ of the failure load, to avoid mandibular fracture. The stiffness of the mandibular specimen was found to be $420 \mathrm{~N} / \mathrm{mm}$ and $643.7 \mathrm{~N} / \mathrm{mm}$ on the contralateral side without fracture.

Before mechanical analysis, the harvested specimens were thawed to room temperature from $-20^{\circ} \mathrm{C}$ for $2 \mathrm{~h}$. All specimens were maintained in moist conditions until the test was completed. Before mechanical testing, mini-plates and screws were removed, including most of the soft tissue around the mandible. Bilateral mandibular coronoid processes and canine cusps were trimmed to prevent interference with the fixation jig during mechanical testing. Into the

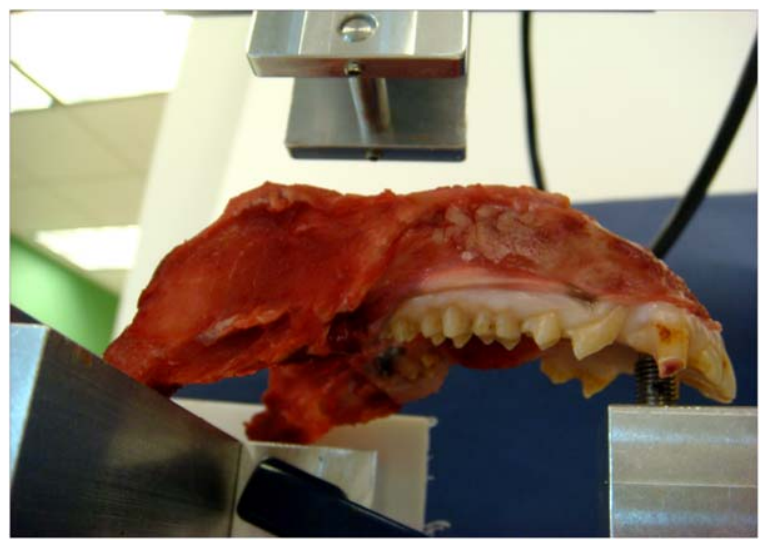

FIGURE 4. Each of the mandibles was placed on the three-point bending jig for biomechanical testing with the Alliance RT/30 Elite ${ }^{\mathrm{TM}}$ Controller. The jig model was designed by the Department of Biomedical Engineering, University of Michigan, Ann Arbor. The mechanical testing system was exposed to compression loads that simulated masticatory loads on each side of the mandible (reconstructed and nonreconstructed sides). Vertical linear displacement was applied by the Alliance RT/30 Elite ${ }^{\mathrm{TM}}$ Controller machine. [Color figure can be viewed in the online issue, which is available at wileyonlinelibrary.com.] 
anterior lingual bone of each mandible, a 3-mm hemisphere was drilled by means of a surgical round bur to prevent displacement of the specimen during force application. Mechanical testing was done for both sides of the mandible at a displacement rate of $0.25 \mathrm{~mm} / \mathrm{min}$ until $111.201 \mathrm{~N}$ was reached. The maximum applied moment (MAM) or maximum moment at failure (MMF) point due to the conclusion of bending force application was stopped before the breaking failure point of each specimen. Force and displacement as well as elastic stiffness $(\mathrm{N} / \mathrm{mm})$ were recorded. Unstable mandibular specimens were excluded from mechanical testing. After mechanical analysis, specimens were immersed in $10 \%$ formaldehyde for subsequent histological preparation and analysis.

\section{Histological analysis}

All histological processing and specimen analyses were performed at the Department of Biomaterials of the Radboud University Nijmegen Medical Centre, The Netherlands.

The specimens were reduced in size, dehydrated in a graded series of ethanol, embedded in methyl methacrylate resin, and polymerized. The tissue blocks were mounted in a modified inner circular saw microtome (Leica ${ }^{\circledR}$ RM 2165, Wetzlar, Germany), and $10-\mu \mathrm{m}$-thick sections were prepared. Serial bucco-lingual cross-sections were stained with methylene blue and basic fuchsin for histology and histomorphometric analysis. At least seven bucco-lingual histological cross-sections were prepared from the reconstructed mandible from each specimen, that is, one at the midline of the device's body, three at the junction between the device body and the stem, and three at the midpoint of the scaffold's stem (Figure 5).

Light microscopy (Leica ${ }^{\circledR}$, Rijswijk, The Netherlands) was used for histological evaluation, which included a general description of the tissue surrounding the implant's body, the junction of the body and the scaffold's stem, and the stem areas.

Histomorphometric analysis was performed by one observer (CN). A modified hard-tissue histologic grading scale $^{31}$ (Table I) was used to quantify the histological findings. The score of each sample was calculated. Total bone contact (TBC) (\%) and bone volume (BV) (\%) were measured for at least three sections of the stem, junction, and mid-scaffold.

Total bone contact (TBC) (\%) at the stem was quantified by microscopy at $5 \times$ and $10 \times$ magnification (Zeiss ${ }^{\circledR}$ computer program). TBC (\%) was calculated with the ImagePro ${ }^{\circledR} 5.0$ system (Media Cybernetics, Silver Spring, MD). TBC (\%) was calculated according to the formula

$$
\text { TBC }(\%)=\frac{\text { Total length of bone interface }}{\text { Total length of stem surface }} \times 100 \text {. }
$$

The mean bone volumes (\%) were calculated $2 \mathrm{~mm}$ from the stem surface (Figure 6). Bone volumes were calculated with the QWin computer program (Q-win;Leica ${ }^{\circledR}$, Wetzlar, Germany) using the average value of three parallel slices and according to the formula
Bone volume (\%)

$\frac{\text { Total bone volume }(- \text { area of tooth or plate } / \text { screw })}{\text { Calculated area } 2 \mathrm{~mm} \text { from the stem surface }} \times 100$.

\section{Statistical analysis}

Data from the mechanical tests were described by stiffness values.

Data on bone regeneration from the micro-CT study and data on histological measurements were statistically analyzed with SAS 9.2 statistical software (SAS Institute, Cary, NC). Measurements were evaluated by analysis of variance (ANOVA) with a pair-wise comparison post-test to identify the groups that differed from each other. This was done without correction for Type I error rate across the pair-wise tests. A $p$ value $<0.10$ was considered statistically significant.

\section{RESULTS}

\section{Gross view and clinical findings}

Although all 24 animals survived the experimental period and maintained their body weight well, at retrieval only 14 specimens were found to be useful for further assessment (PCL [control] [ $n=3$ ], PCL-BMP $[n=6]$, and PCL-CELL [ $n$ $=5]$ ). The rest of the animals had to be excluded due to loosen plates and screw, clinical mobility, and wound infection at the reconstruction sites (Figure 7).

Serial radiographic examinations and gross examination showed incomplete union between bone segments in all groups at 6 months after surgery. Radiographic bone formation was found to be higher in the PCL-BMP than in the PCL-CELL and PCL (control) groups, and regenerated bone was also found outside the scaffold, especially in the area adjacent to the lingual periosteum. The fixation plates and screws appeared to be loose in some specimens (Figure 8).

\section{Micro-CT analysis}

Micro-CT revealed that bone regeneration in the various PCL scaffold groups never resulted in complete repair of the continuity defects at 6 months. Deformation of the scaffold, that is, bending or fracture between the stem and the body of the scaffold, was found in two specimens (PCL-control and PCL-CELL). The lingual side of the mandibular defect showed homogeneous bone regeneration.

Calculated mean bone volume $\left(\mathrm{mm}^{3}\right)$ at the reconstruction side (area between mandibular segments) was found, for PCL-control, PCL-CELL, and PCL-BMP, to be $210.07 \pm$ 112.37, 566.66 \pm 371.30, and $481.98 \pm 281.60 \mathrm{~mm}^{3}$, respectively. However, bone formation presented mainly at the lingual side of the defect, and some regenerated bone was separated from the scaffold. Further evaluation of new bone formation inside the scaffold structures revealed a high level of bone formation in the PCL-BMP group compared with the other groups (Figure 10). Mean bone volume inside the scaffold for PCL-control, PCL-CELL, and PCL-BMP was $27.98 \pm 34.64,9.21 \pm 7.42$, and $153.45 \pm 171.42$ $\mathrm{mm}^{3}$, respectively.

The mean tissue mineral content (TMC) for PCL-control, PCL-CELL, and PCL-BMP was $14.15 \pm 17.34,4.87 \pm 4.08$, 


\section{Histology Section Areas}

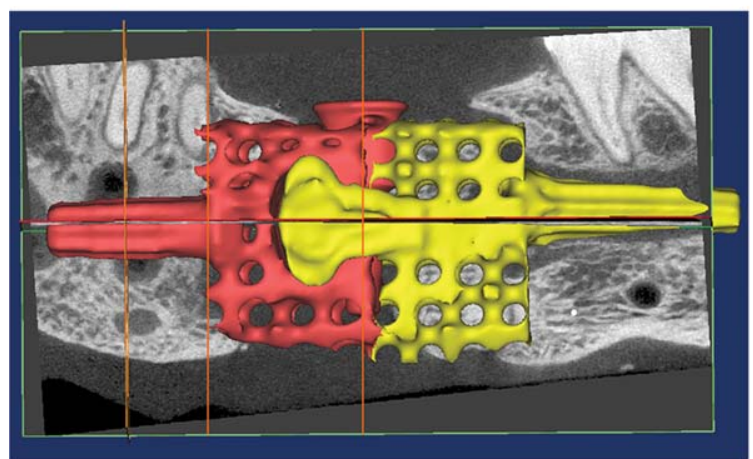

(1) (2)

(3)

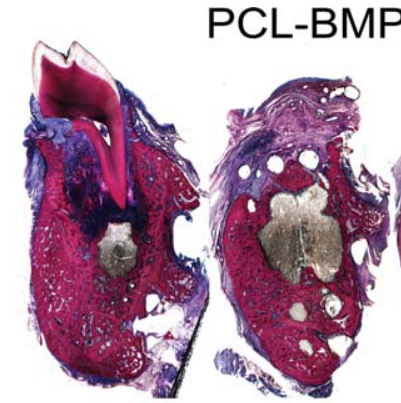

(1)

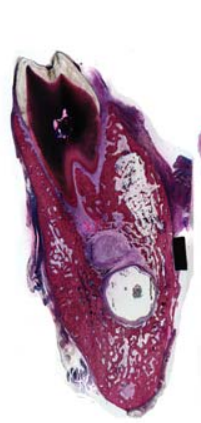

(1)

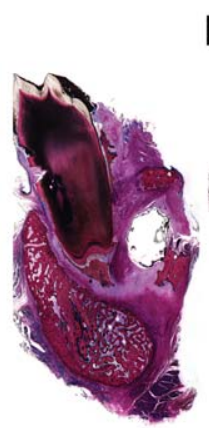

(1)
(2)

PCL-CELL

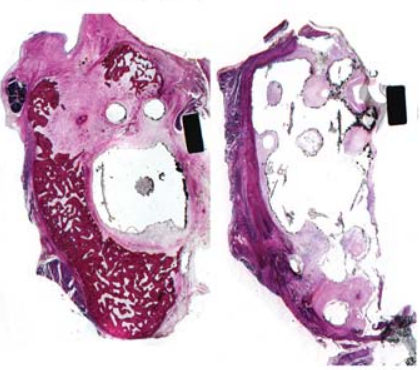

(2)

(3)

\section{(1) Section at the stem of \\ (2) Junction between the stem and the body of the scaffold \\ (3) Mid-scaffold section}

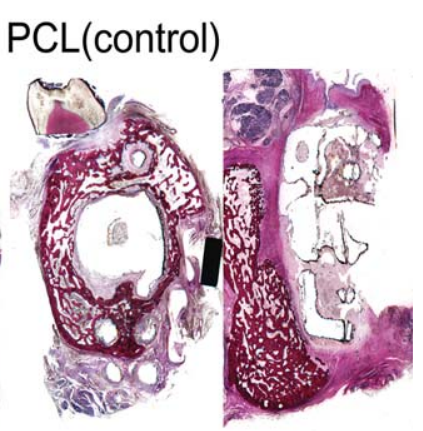

(2)

(3)

FIGURE 5. Histology slide sections (magnification $\times 1$ ) from three areas of the scaffold: (1) the stem of the scaffold, (2) the junction between the stem and the body of the scaffold, (3) and a mid-scaffold section. The sections showed better bone formation inside the scaffold structure of the PCL-BMP group, while mostly fibrous tissue was found in the PCL-CELL and PCL-control groups. The stem of the scaffold in the PCL-BMP group was surrounded with bone, while fibrous connective tissue was again found in the other two groups. [Color figure can be viewed in the online issue, which is available at wileyonlinelibrary.com.]

and $82.96 \pm 91.33 \mathrm{mg}$, respectively, and the mean tissue mineral density (TMD) for PCL-control, PCL-CELL, and PCL$\mathrm{BMP}$ was $521.48 \pm 25.59,491.62 \pm 60.73$, and $547.23 \pm$ $40.13 \mathrm{mg} \mathrm{HA} / \mathrm{mL}$, respectively. Nevertheless, statistical analysis demonstrated that the observed differences in bone volume (outside and inside), TMC, and TMD between and among the various groups were not significant $(p>0.10)$ (Figures 9 and 10).

\section{Mechanical testing}

Successful mechanical testing could be undertaken only on four specimens, that is, PCL-BMP $(n=2)$ and PCL-CELL ( $n$ $=2$ ), while the other four specimens presented with poor stability at the reconstruction site, which did not allow for mechanical assessment. The stiffness values on the experimental side of the mandible were 7.1 and $24.4 \mathrm{~N} / \mathrm{mm}$ in the PCL-CELL group and 193 and $61.9 \mathrm{~N} / \mathrm{mm}$ in the PCLBMP group. The mean stiffness values on the contralateral side of the mandible were 129.4 and $198.2 \mathrm{~N} / \mathrm{mm}$ in the PCL-CELL group and $820.9 \mathrm{~N} / \mathrm{mm}$ in the PCL-BMP group. The peak load, reported as $40.41 \mathrm{~N}$, was found in one of the two samples from the PCL-CELL group and also in one sample of the PCL-BMP group, which was found to be at 72.09 $\mathrm{N}$ (Figure 11).

\section{Analysis by light microscopy}

Successful histological analysis was performed on 14 specimens, that is, PCL-BMP $(n=6)$, PCL-CELL $(n=5)$, and 
TABLE I. Hard-Tissue Histologic Grading Scale (Adapted and Modified from Jansen et al. ${ }^{31}$

\begin{tabular}{ll}
\hline Parameter & \multicolumn{1}{c}{ Score } \\
\hline Bone formation & 2: Completely surrounded with bone \\
1: Partially surrounded with bone & 0: No bone (fibrous formation) \\
Bone-device & 2: Completely interfaced with bone \\
interface & 1: Partially interfaced with bone \\
0: No bone (fibrous formation) & 3: Completely disappeared-almost \\
Scaffold & complete degradation or complete \\
degradation & fragmentation \\
& 2: Marked degradation-marked \\
cracks in implant and/or some & fragments toward edges and \\
outer surface & 1: Limited degradation-some \\
minor dissolution on edges, \\
minor cracks in implant, \\
and/or small fragments present \\
0: No degradation-completely \\
intact polymer
\end{tabular}

PCL-control $(n=3)$, while the rest of the specimens were excluded due to infection. The histological sections showed more enhanced bone regeneration in the PCL-BMP than in the PCL-CELL and PCL-control groups (Figure 12). The PCL scaffolds showed minimal signs of degradation in all groups. In detail, the PCL-BMP group showed normalappearing mature trabecular bone both outside and inside of the scaffold's porosity in two of the six specimens. The majority of the cells detected were osteocytes and osteoblasts. The porosity of the PCL-CELL and the control groups was mainly filled with soft tissue, with an abundant presence of fibroblasts and inflammatory cells. Islands of bone were found related to the periosteum, especially at the lingual side, outside the scaffold. At the junction of the body and scaffold stem, bone formation starting from the mandibular stump and progressing into the scaffold porosity and bone was found to be present at the lower border and lingual side of the mandible in three of the six specimens from the PCL-BMP group, two of five specimens from the PCL-CELL group, and one of three specimens from the PCL-control group. Again, the amount of bone formation in this region appeared to be higher for the PCL-BMP group. Around the stems of the scaffolds, a thick connective tissue layer was present between the stem surface and native bone in most specimens. However, direct bone contact at the interface was found in three specimens of the PCL-BMP group and in one of the PCL-control groups.

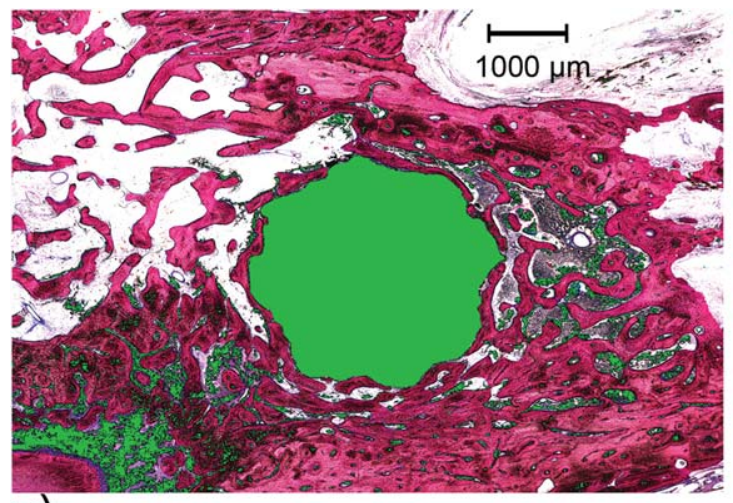

a)

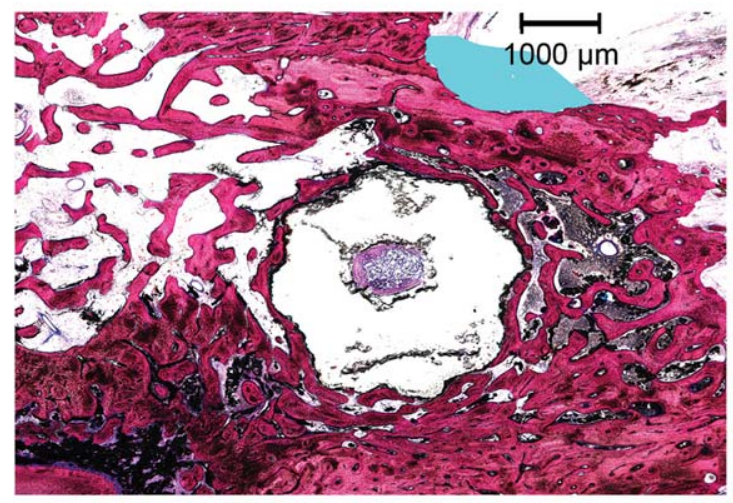

c)

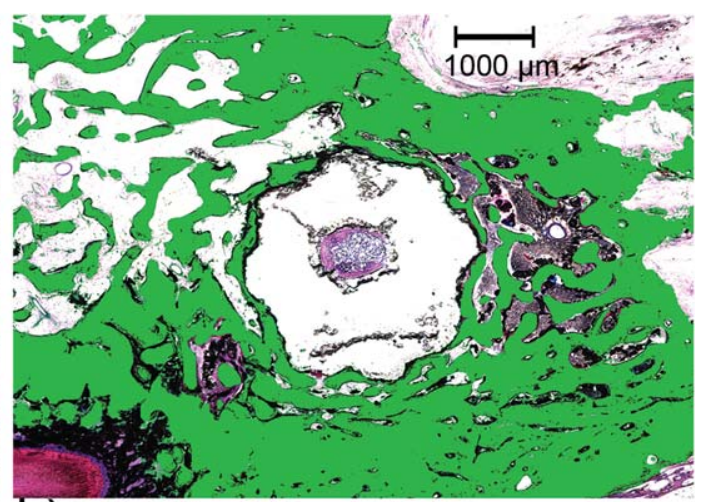

b)

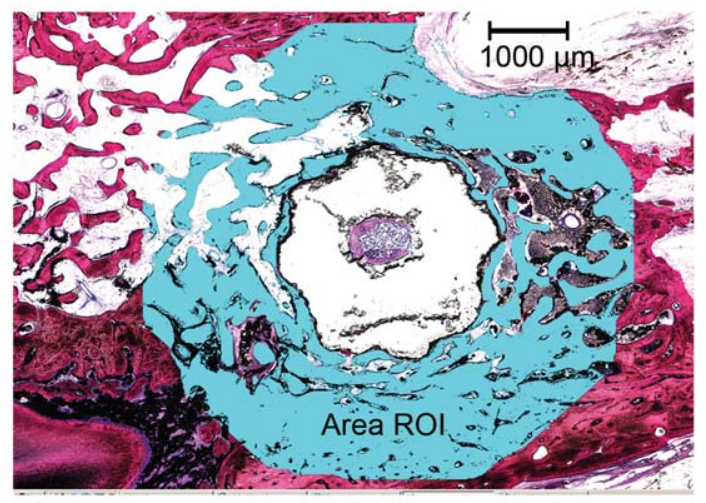

d)

FIGURE 6. The Qwin computer program was used to calculate the percent bone volume from the area $2 \mathrm{~mm}$ around the stem implant surface. The images show the method for identification of the ROI. The computer program identified: (a) the stem area, (b) the bone around the stem, and (c) removal of other defects, that is, screw or root tip. The selected area (ROI) around the scaffold's stem is used to calculate the percent bone volume, as shown in (d). [Color figure can be viewed in the online issue, which is available at wileyonlinelibrary.com.] 


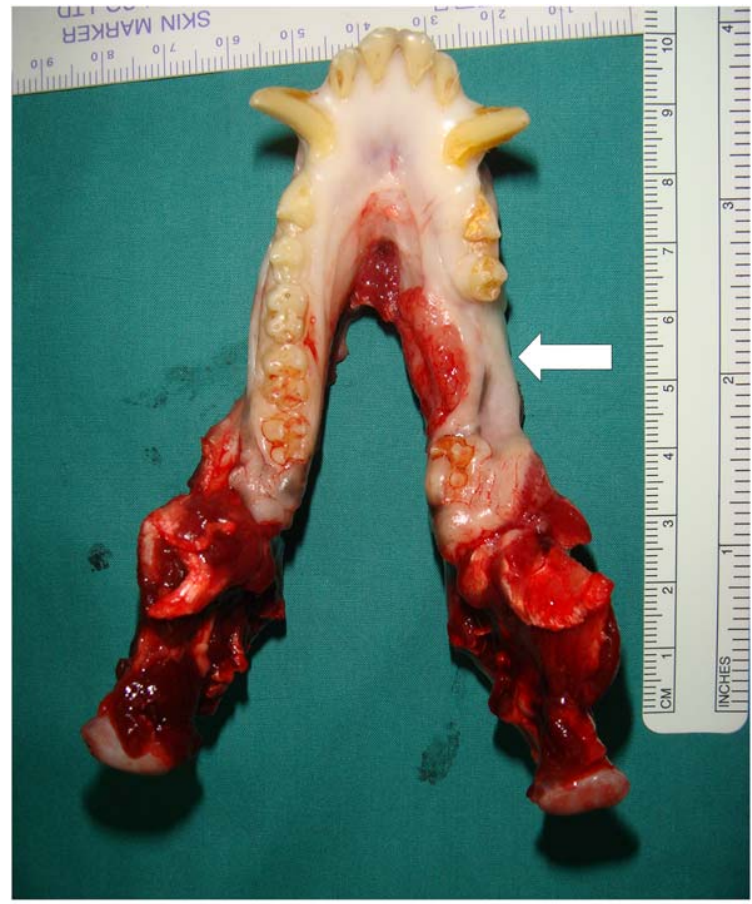

a)

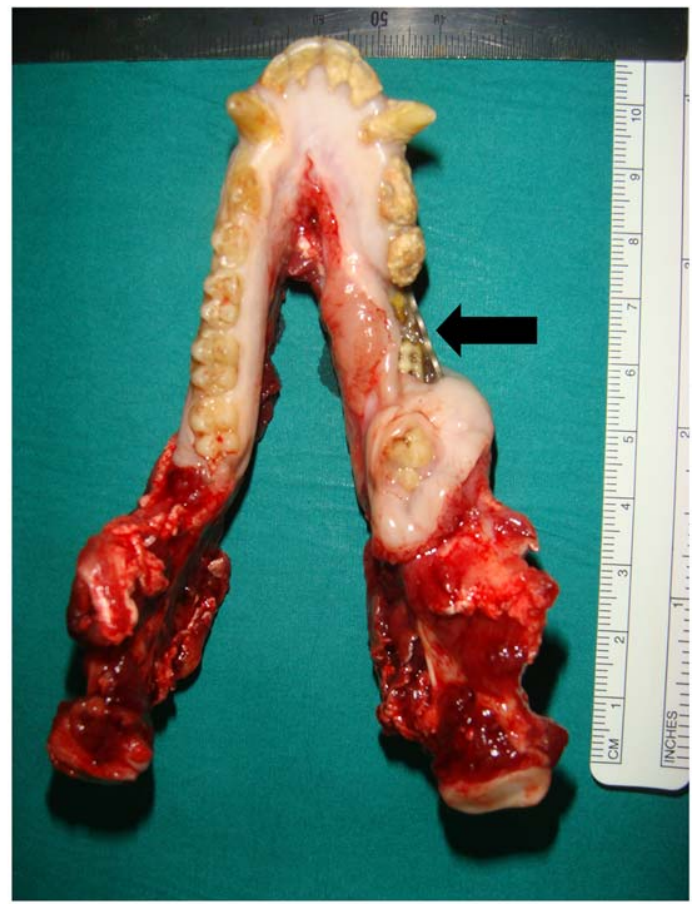

b)

FIGURE 7. Images of reconstructed mandibular specimens at 6 months. Several of the specimens successfully maintained their shape, mandibular contour, and an intact oral mucosa (white arrow) (a), while others presented with wound dehiscence. The scaffold and miniplates are exposed through intraoral wounds (black arrow) (b). [Color figure can be viewed in the online issue, which is available at wileyonlinelibrary.com.]

\section{Histomorphologic analysis}

Bone formation around the device and bone-device interface was analyzed in three areas (mid-scaffold, junction between the scaffold body and stem, and mid-posterior stem), and the grading scale used is depicted in Figures 13 and 14.
The mean total bone presentation grading score for the "area around the devices" was $0.69 \pm 0.01$ for the PCLcontrol group, $0.63 \pm 0.01$ for the PCL-CELL group, and $1.21 \pm 0.29$ for the PCL-BMP group. The difference in total bone presentation score between the PCL-BMP and PCLcontrol groups, and also between the PCL-BMP and PCL-

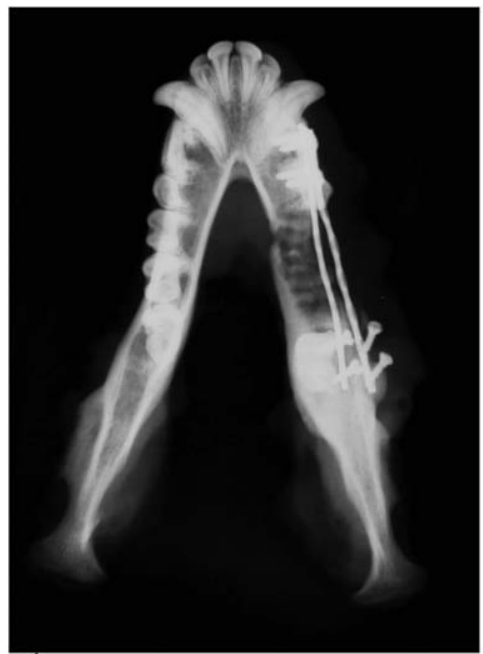

a) PCL-BMP

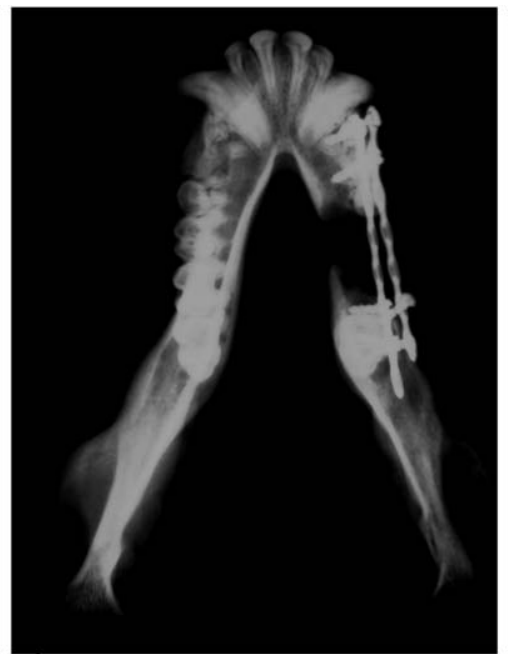

b) PCL-CELL

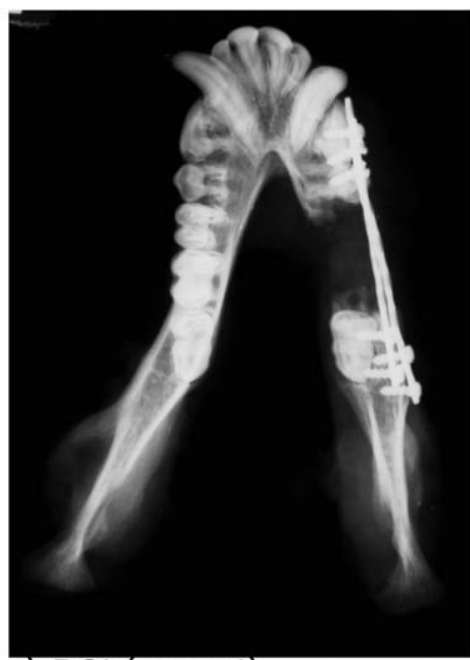

c) PCL(control)

FIGURE 8. Radiographic images of the reconstructed monkey mandibles: (a) PCL-BMP, (b) PCL-CELL, and (c) PCL-control. The mandibles maintained both shape and dimension. The new bone regeneration was found to be nearly complete in the PCL-BMP group. Incomplete bone union was observed in the other two groups. Loosening of plates and screws was found in several specimens. 


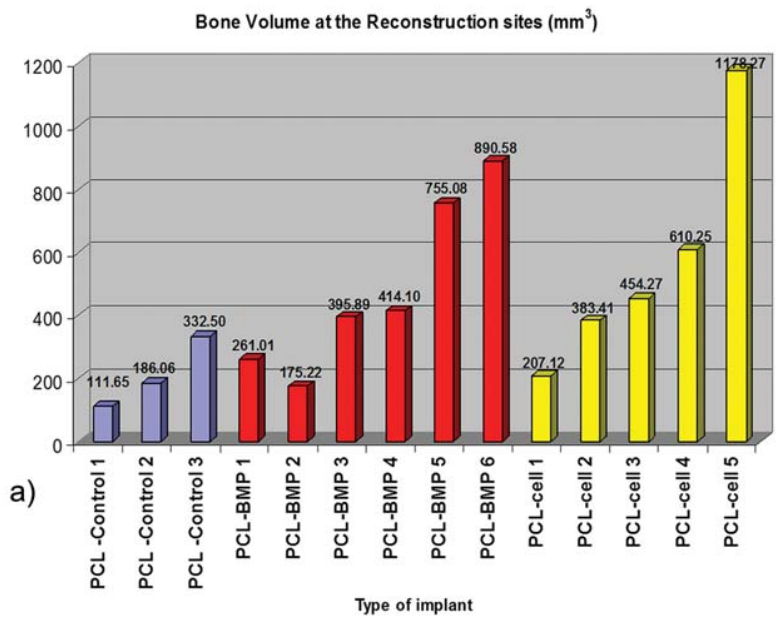

Bone Volume inside the Scaffolds $\left(\mathrm{mm}^{3}\right)$

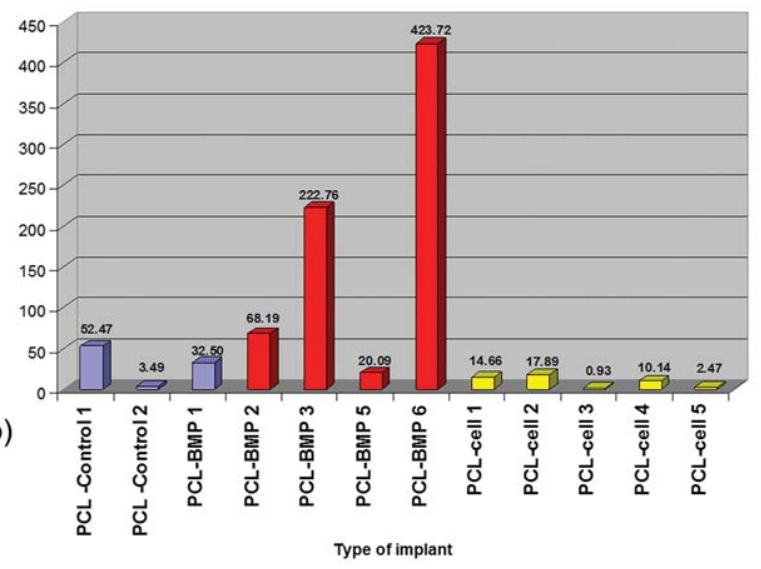

FIGURE 9. Micro-CT scan analysis results. (a) Bone volume at the reconstruction site of each specimen. (b) Bone volume formation inside the PCL scaffold in each specimen. [Color figure can be viewed in the online issue, which is available at wileyonlinelibrary.com.]

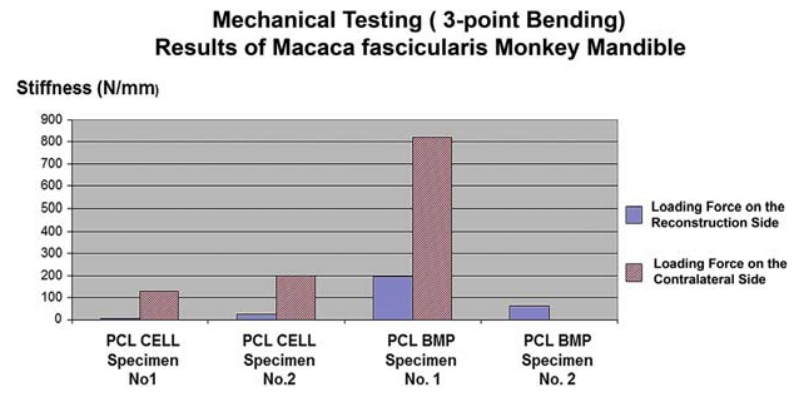

FIGURE 11. Stiffness values of three-point bending in monkey mandibles. Stiffness value in the PCL-CELL is 7.1 and $24.4 \mathrm{~N} / \mathrm{mm}$ while loading force was applied to the experimental side and 129.4 and $198.2 \mathrm{~N} /$ $\mathrm{mm}$ with force applied to the contralateral side. Stiffness value in PCL-BMP is 193 and $61.9 \mathrm{~N} / \mathrm{mm}$ while loading force was applied to the experimental side and $820.9 \mathrm{~N} / \mathrm{mm}$ with force applied at the contralateral side. Mechanical testing could not be performed on any of the PCL-control specimens, due to weakness at the reconstruction site. [Color figure can be viewed in the online issue, which is available at wileyonlinelibrary.com.]

CELL groups, was found to be statistically significant $(p<$ $0.10)$. There was no statistically significant difference between the PCL-control and PCL-CELL groups.

The mean total grading scores for the "bone-device interface" were $0.19 \pm 0.29$ for the PCL-control group, 0.12 \pm 0.15 for the PCL-CELL group, and $0.55 \pm 0.46$ for the PCL-BMP group. Statistical testing revealed no significant differences in the mean total grading scores between and among groups.

The percentages of bone-device interface calculated around the stem of the implant to the native bone were $2.26 \% \pm 5.30$ for the PCL-control group and $2.96 \% \pm 5.01$ for the PCL-BMP group, and there was no bone-device interface $(0 \%)$ in the PCL-CELL group. There were no statistically significant differences between the PCL-control and PCL-BMP groups.

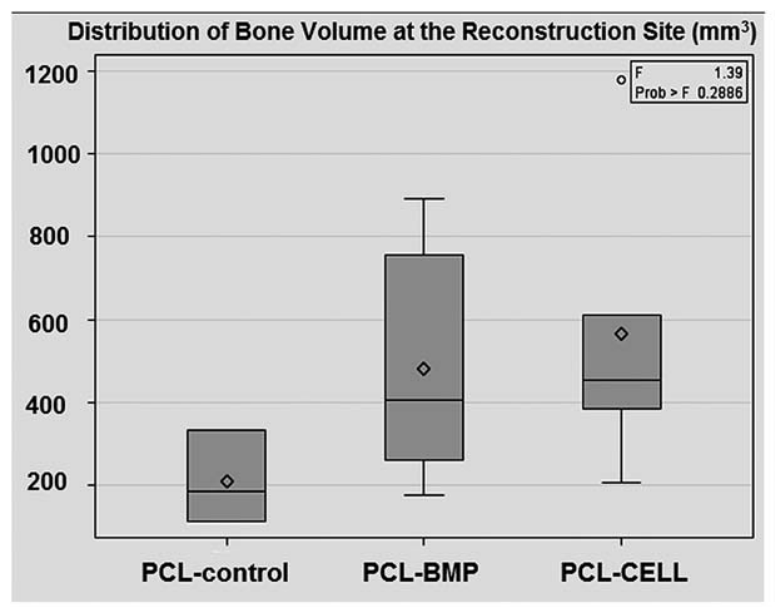

a)

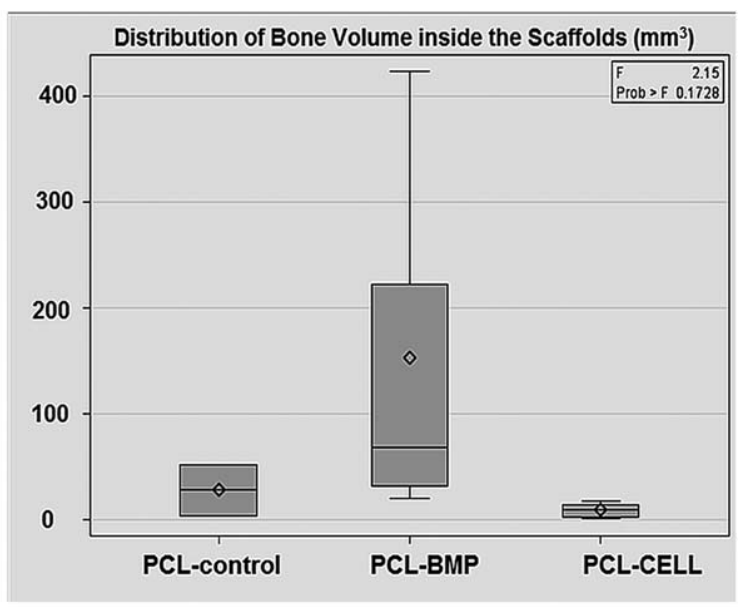

b)

FIGURE 10. Micro-CT scan analysis. (a) Mean bone volume at the reconstruction site of each specimen. (b) Mean bone volume inside the PCL scaffold. There was no significant difference in mean bone volume at the reconstruction site and inside the scaffold among the three groups ( $p$ $>0.010)$. 


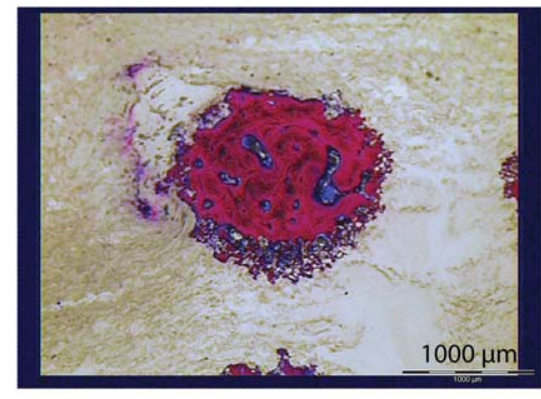

a) PCL-BMP (x 4)

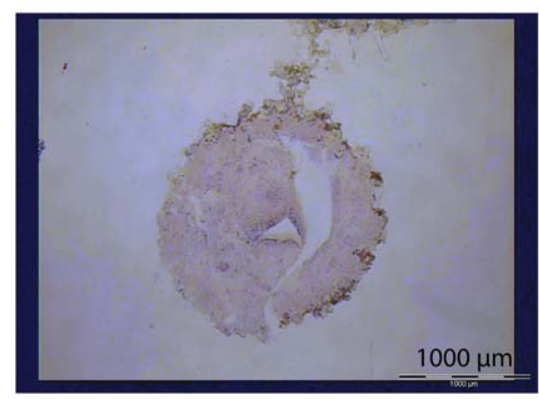

d) PCL-CELL (x4)

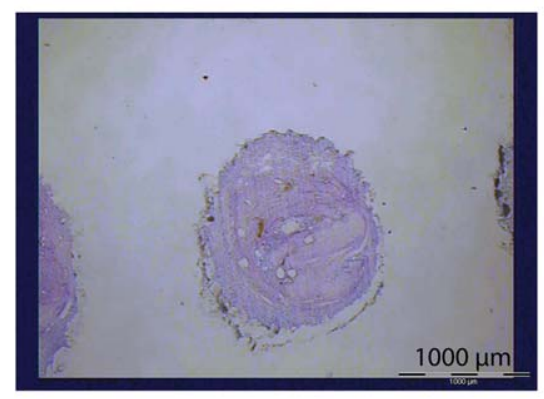

g) PCL(control) (x4)

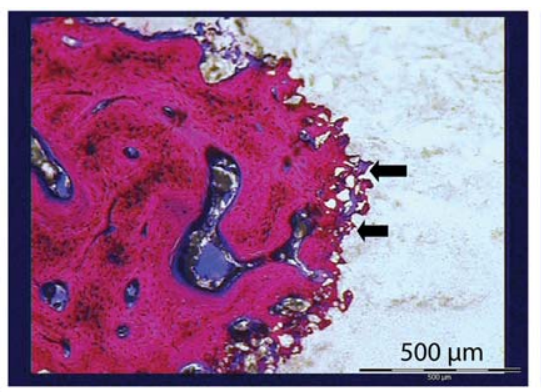

b) PCL-BMP (x10)

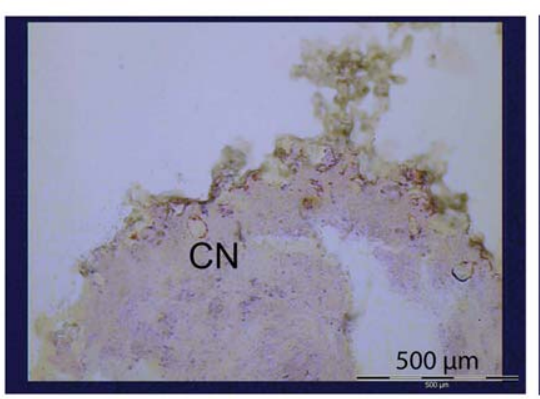

e) PCL-CELL (x10)

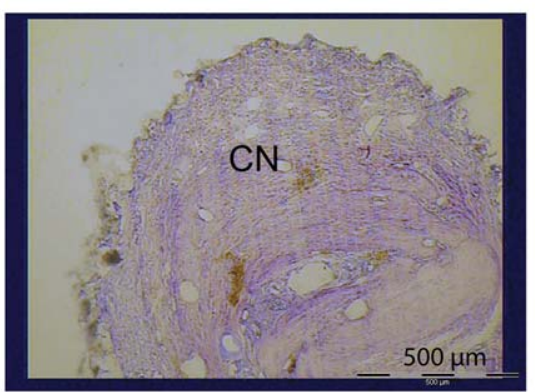

h) PCL(control) (x10)

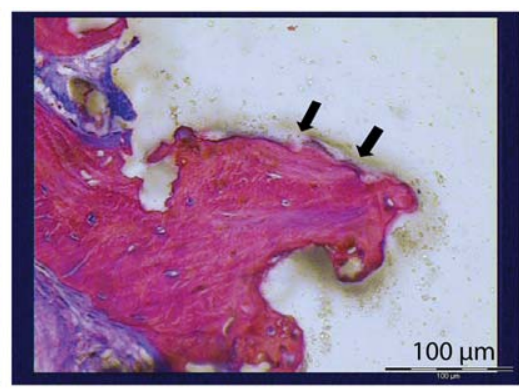

c) PCL-BMP (x40)

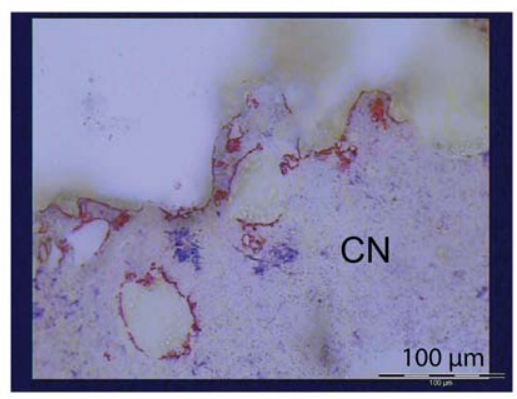

f) PCL-CELL(x40)

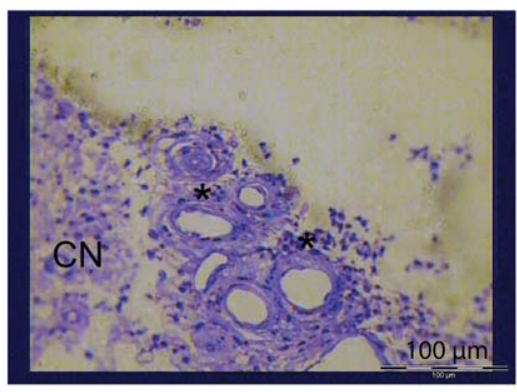

i) $\mathrm{PCL}$ (control) (x40)

FIGURE 12. Histology slide sections of scaffold porosity at the mid-scaffold region: PCL-BMP (a) to (c), PCL-CELL (d) to (f), and PCL-control (g) to (i). Bone formation was found in PCL-BMP scaffold pores, while connective tissue was observed in the other two groups. Good bone-scaffold contact with areas of scaffold degradation was seen along the edge in the PCL-BMP group. CN $=$ connective tissue, *inflammatory cells, and arrows $=$ bone-scaffold contact areas. [Color figure can be viewed in the online issue, which is available at wileyonlinelibrary.com.]

The mean scores for scaffold degradation were 0 for the PCL-control group, 0 for the PCL-CELL group, and $0.78 \pm$ 0.43 for PCL-BMP groups [Figure 14(d)].

The results of the bone contact and bone volume percentages, as determined with image analysis software, are depicted in Figure 15. The differences in mean percent bone volume (\%), calculated in the area of $2 \mathrm{~mm}$ around the stem implant surface, were $27.67 \% \pm 0.19$ for the PCLcontrol group, $32.65 \% \pm 15.58$ for the PCL-CELL group, and $56.33 \% \pm 6.98$ for the PCL-BMP groups. The mean percent bone volume between the PCL-BMP and PCL-CELL groups and between the PCL-BMP and PCL-control groups was found to be statistically significant $(p<0.10)$ among the groups. There was no statistically significant difference between the PCL-control and PCL-CELL groups.

\section{DISCUSSION}

This study is the first attempt to reconstruct a mandibular body segmental defect using the endoprosthesis-designed PCL scaffold combined with either rhBMP-2 or autologous bone marrow cells in a non-human primate model. The continuity defect of segmental resection in the study was similar to those resulting from ablative surgery, for example, trauma, tumors, or osteomyelitis in the oral and maxillofacial region. We proposed to compare the degrees of bone regeneration that occurred from the PCL scaffold reconstruction resulting from the addition of either rhBMP-2 or autologous bone marrow cells.

M. fascicularis monkeys were selected in this study due to their anatomic and biological mandibular similarity to humans. $^{3,32}$ The 6-month follow-up period was considered 
Score of Bone Presentation around Mid-body Area of Scaffold ( Center of the Reconstruction Site)

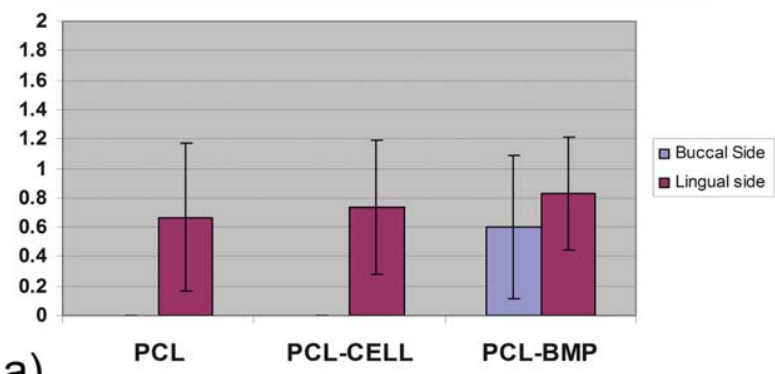

a)

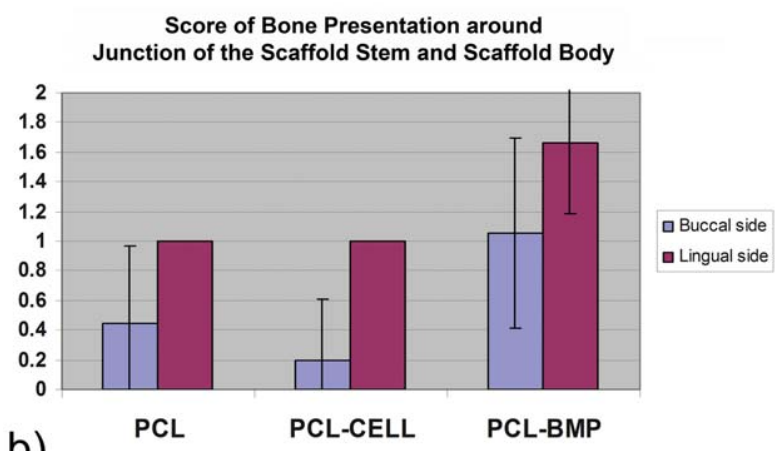

b)

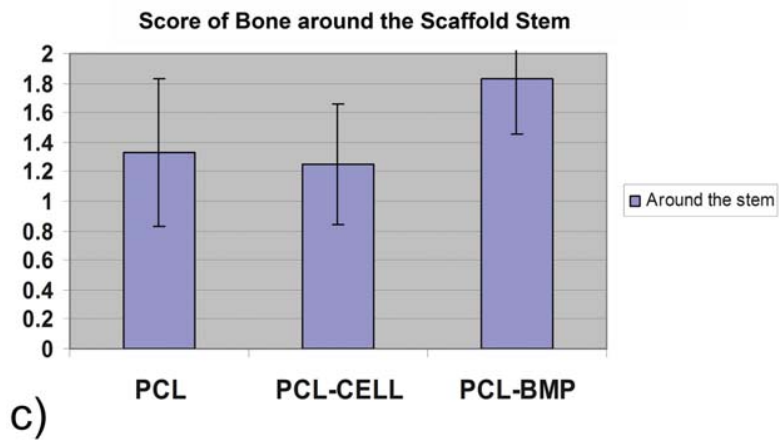

FIGURE 13. Bone present around the scaffolds: (a) mid-body, (b) junction, and (c) scaffold stem. The score scale: 0 , no bone (fibrous formation); 1, partially surrounded with bone; and 2, completely surrounded with bone. [Color figure can be viewed in the online issue, which is available at wileyonlinelibrary.com.]

suitable based on results from previous studies on the similar healing of a defect site in the same model evaluating bone bridge formation in a mandibular continuity defect by a tissue-engineering technique, ${ }^{16,33-36}$ including reconstruction with a titanium alloy modular endoprosthesis. ${ }^{5}$ Although the non-primate human model is closed to clinical study, the immobilized jaw movement by the inter-maxillary fixation (IMF) cannot be performed, unlike in humans. Therefore, the identification of an alternative method for early stabilization of the reconstruction site was crucial. Although the addition of internal fixation with two miniplates and screws was used to maintain the mandibular integrity of bone segments in the study, unfortunately, the results demonstrated insufficient load-bearing capacity in most of the animals, and, subsequently, infection was found in many specimens.
The immediate loading force and the intra-oral surgical approach appeared to be related to wound dehiscence and disrupted the achievement of bone union. Wound dehiscence was experienced by the animals as an "uncomfortable feeling" and resulted in additional disturbance of the wounds by the monkeys with their fingers. Wound dehiscence as well as dislodgement of the mini-plates and screws led to a limited number of appropriate specimens for further evaluation. Therefore, the data should be interpreted with caution.

There was incomplete bone union in all study groups; therefore, we rejected the hypothesis that an osteoinductive scaffold loaded with rhBMP-2 or bone marrow cells could achieve bone union and overlying soft-tissue healing with sufficient load-bearing capacity within 6 months. However, the findings showed that the amount of bone in-growth was higher in the PCL-BMP-2 group compared with that in the PCL-CELL and PCL-control groups. The micro-CT imaging in one specimen from the PCL-BMP group showed a nearly complete bone union with bone in-growth. The mechanical test showed that the mandible reconstructed with PCL-BMP had a higher load-bearing capacity compared with that of the other groups. Nonetheless, with the limitation that the study was discontinued at 6 months, it might be possible that bone formation and bone union in the PCL-BMP group may or may not continue if a follow-up period was set at more than 6 months. However, based on the current findings, the PLC-BMP-2 reconstruction has potential for bone regeneration in mandibular continuity defects.

Basic bone bioengineering can be accomplished relative to many factors, including bone scaffold, growth factors, biologic cells, and surrounding vascular blood supply, especially in large reconstruction sites. ${ }^{37,38}$ The ideal biomaterial properties for bone scaffolds were identified as biocompatibility, a capacity for facilitating revascularization, osteoinductive, and osteoconductive properties, and a structure providing a framework for new bone development while allowing for the incorporation of osteogenic factors. ${ }^{38}$ Furthermore, the material should be easily shaped into complex components, as well as being malleable, sterilizable, storable, and affordable. The material stiffness should offer an initial primary stability for the reconstruction site with subsequent gradual degradation corresponding with newly deposited bone ingrowth, to maintain the proper load-bearing capacity. The candidate scaffold materials that closely fulfill such requirements are bioresorbable aliphatic polyesters, such as polyglycolide, polylactide, PCL, and their copolymers.

PCL is the FDA-approved material used in multiple medical device formulations. ${ }^{12}$ It already has a significant history of regulatory approval, with minimal inflammatory and immunological responses, ${ }^{39,40}$ and has been used in clinical applications highly biocompatible with osteoblasts. The thermoplastic quality of PCL allows it to be processed in three dimensions with the desired geometry, and for controlled porosity with interconnectivity by modern computerbased solid free-form fabrication technology. In this study, the scaffold was designed to follow the anatomy of a monkey mandible based on the computed scan (CT) data. It was 
Score of Bone -Scaffold Interface at Mid Scaffold
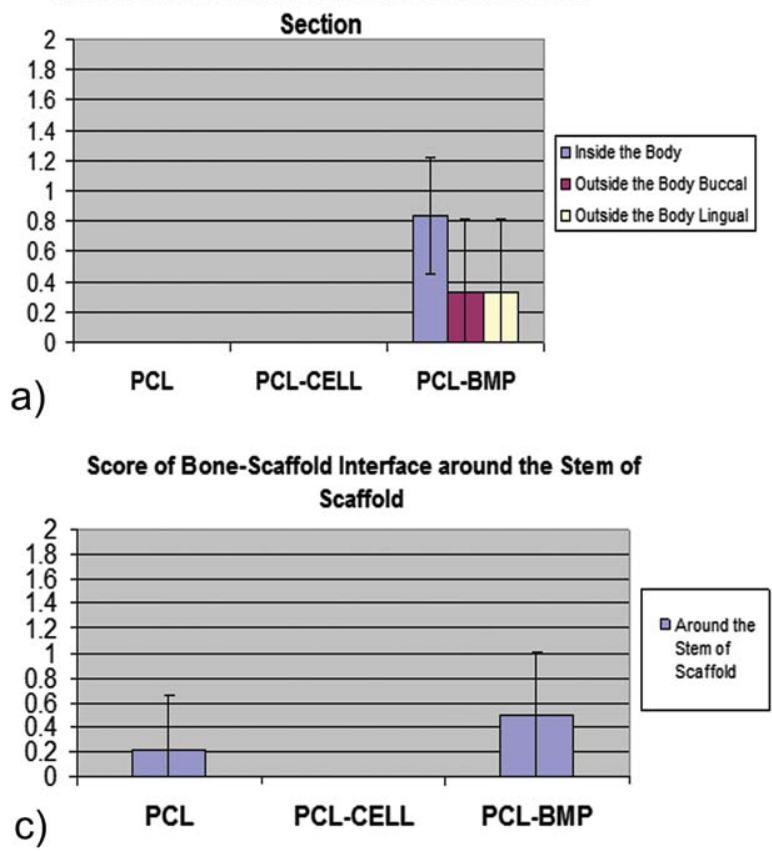

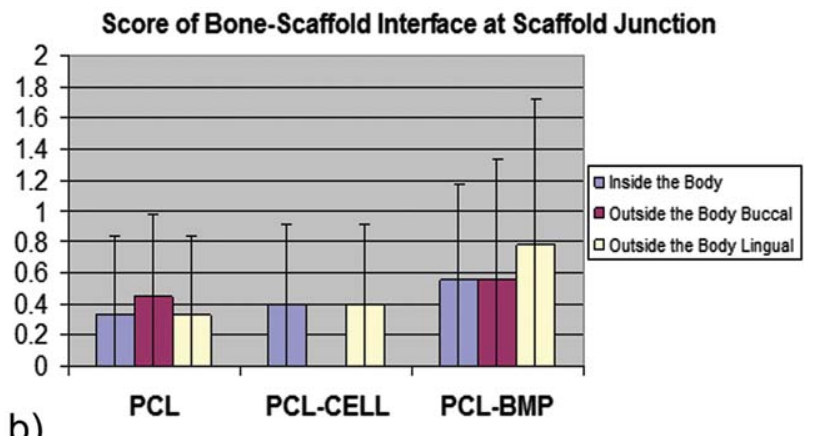

b)

Percent Bone interface around the Stem of the Scaffold (\%) and Score of Scaffold Degradation

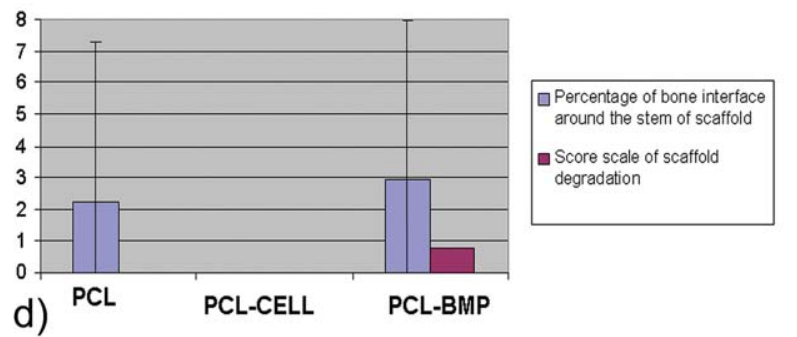

FIGURE 14. Scoring of bone-scaffold interface at three areas: (a) mid-body, (b) junction, and (c) scaffold stem. 0 , No bone (fibrous formation); 1 , partial interface with bone; and 2, complete interface with bone. Percentage of bone interface around the stem of the scaffold and scoring of scaffold degradation are shown in (d). Score scale for scaffold degradation is described as: 0 , no degradation; 1 , limited degradation; 2 , severe degradation; and 3, bone has completely disappeared. [Color figure can be viewed in the online issue, which is available at wileyonlinelibrary.com.]

comprised of a body segment with two modular endoprosthesis stems inserted into the prepared cancellous cavity of a native mandible. The PCL scaffold was intended to maintain the stability of the mandible and to support the anatomical regeneration of the bone defect.

Among growth factors for the enhancement of bone regeneration, BMPs have been reported to be successful in bone reconstruction. The selected carriers reported in the literature were collagen sponges, ${ }^{16,35,41,42}$ poly-D,L-lactic-coglycolic acid-coated gelatin sponges (PGS), ${ }^{43}$ poly-D,L-lactic coglycolic acid (PLGA)-coated gelatin sponges (PGS), ${ }^{44}$ polyglycolic co-lactic acid (PGLA), ${ }^{45}$ and autologous bone graft of freeze-dried bone. ${ }^{46}$ Among these materials, the collagen type-I sponge was found to be the most frequently used in preclinical and clinical studies in segmental mandibular reconstruction with promising results. However, the collagen sponge lacks sufficient structural integrity to maintain the defect space compared with a bone graft and also lacks loading capacity. ${ }^{18}$ Therefore, there is great interest in the search for other bone scaffold carriers better suited to bone defect repair. ${ }^{18}$ PCL is a candidate material. Although it has non-osteoinductive properties, an engineered CHA surface coating on PCL has been proven to allow protein molecules such as rhBMP-2 to attach and be released in a controlled manner, ${ }^{12,13}$ as was used in this study.

The porosity of the scaffold functions as a repository for housing bone marrow mesenchymal cells to be transported to the reconstruction site. The autologous bone marrow cells used in this study were aspirated from the autologous trochanter bone, as we noted that the monkey's iliac bone size was small. The autologous bone marrow cells were processed and seeded into the scaffolds for reconstruction without the in vitro incubation process, so that the bone reconstruction process could be completed within the same operation. This approach was found to compromise the function and morphogenic ability of the bone marrow cells possibly related to poor cell viability after implantation. The bone regeneration results in the PCL-CELL group were complicated by wound infection without bone in-growth. The lack of bone formation in the center of the scaffold possibly resulted from insufficient blood supply to the inner side of the scaffold structure, required to maintain cell survival. The results therefore did not differ from those of the control group. The conclusions resulting from the use of a PCL

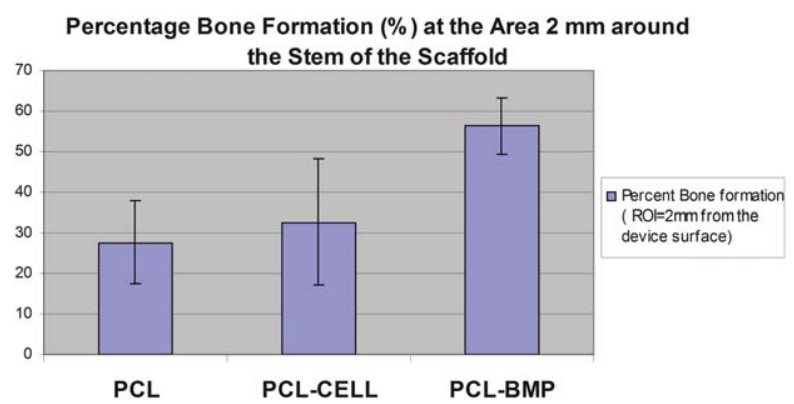

FIGURE 15. Percentage bone volume (\%) calculated from the ROI (area $2 \mathrm{~mm}$ around the scaffold stems). [Color figure can be viewed in the online issue, which is available at wileyonlinelibrary.com.] 
scaffold combined with autologous bone marrow cells yielded insufficient supporting data. The methodology on cellular approaches to bone regeneration requires further study.

The acknowledged slow degradation phenomenon of PCL, which depends on random hydrolytic chain scission of the ester linkages, may vary from months to years. ${ }^{47}$ Polymer degradation can be characterized as a decrease in the rate of chain scission and the onset of implant weight loss, fragmentation, and intracellular degradation. ${ }^{48}$ This slow degradation could even hamper bone in-growth. The PCL scaffold degradation in this study was limited, and the remaining structure was still present at the end of the study. However, the actual amount of PCL degradation, for example, molecular weight loss, was not evaluated in this study.

Further studies will be needed to determine the optimal methodology and parameters prior to clinical use. In future studies, additional steps can be taken to increase the stability of the endoprosthesis. A surgical approach to mandibular reconstruction should preferably be performed extra-orally to reduce wound dehiscence and infection rates. PCL can be the material of choice; however, after insertion into the mandible, the modular components of the scaffold can be heat-welded together to increase the rigidity of the prosthesis. Importantly, sufficient rigid plate(s) fixation should be used to improve the primary stability of the reconstructed site, especially in the initial stage of reconstruction. The protocol for bone marrow cell preparation and seeding requires revision if promising results are to be achieved.

\section{CONCLUSION}

In conclusion, the results of our study did not confirm the original hypothesis. Based on the data obtained, no satisfactory bone formation occurred between the mandibular segments at 6 months after surgery in any of the three groups. There was a high rate of infection and dislodgement of the fixation plates and the PCL endoprosthesis scaffold. Nevertheless, the BMP-2-loaded PCL scaffolds were found to perform better in terms of bone formation and mechanical testing than empty PCL scaffolds and scaffolds loaded with autogenous BMSCs. This suggests that this might be a feasible approach for further study in reconstructing segmental mandibular defects.

\section{ACKNOWLEDGMENTS}

The authors thank the staffs from the Department of Biomedical Engineering, College of Engineering, University of Michigan, and Tissue Regeneration Systems, Ann Arbor, MI, for manufactured and supplied PCL scaffolds, and Assistant Professor John C. Allen from the Centre for Quantitative Medicine, Duke-NUS Graduate Medical School, Singapore, for assisting in statistical analysis.

\section{REFERENCES}

1. Chim H, Salgado CJ, Mardini S, Chen HC. Reconstruction of mandibular defects. Semin Plast Surg 2010;24:188-197.
2. Hadlock TA, Vacanti JP, Cheney ML. Tissue engineering in facial plastic and reconstructive surgery. Facial Plast Surg 1998;14:197203.

3. Lee S, Goh BT, Tideman H, Stoelinga PJ. Modular endoprosthesis for mandibular reconstruction: A preliminary animal study. Int $\mathrm{J}$ Oral Maxillofac Surg 2008;37:935-942.

4. Wong RC, Lee S, Tideman H, Merkx MA, Jansen J, Liao K. Effect of replacement of mandibular defects with a modular endoprosthesis on bone mineral density in a monkey model. Int $\mathrm{J}$ Oral Maxillofac Surg 2011;40:633-639.

5. Lee S, Goh BT, Tideman H, Stoelinga PJ, Jansen JA. Modular endoprosthesis for mandibular body reconstruction: A clinical, micro-CT and histologic evaluation in eight Macaca fascicularis. Int J Oral Maxillofac Surg 2009;38:40-47.

6. Rai B, Ho KH, Lei Y, Si-Hoe KM, Jeremy Teo CM, Yacob KB, Chen F, Ng FC, Teoh SH. Polycaprolactone-20\% tricalcium phosphate scaffolds in combination with platelet-rich plasma for the treatment of critical-sized defects of the mandible: A pilot study. J Oral Maxillofac Surg 2007;65:2195-2205.

7. Schuckert $\mathrm{KH}$, Jopp S, Teoh SH. Mandibular defect reconstruction using three-dimensional polycaprolactone scaffold in combination with platelet-rich plasma and recombinant human bone morphogenetic protein-2: De novo synthesis of bone in a single case. Tissue Eng Part A 2009;15:493-499.

8. Hollister SJ, Lin CY, Saito E, Lin CY, Schek RD, Taboas JM, Williams JM, Partee B, Flanagan CL, Diggs A, Wilke EN, Van Lenthe GH, Müller R, Wirtz T, Das S, Feinberg SE, Krebsbach PH. Engineering craniofacial scaffolds. Orthod Craniofac Res 2005;8: 162-173.

9. Williams JM, Adewunmi A, Schek RM, Flanagan CL, Krebsbach $\mathrm{PH}$, Feinberg SE, Hollister SJ, Das S. Bone tissue engineering using polycaprolactone scaffolds fabricated via selective laser sintering. Biomaterials 2005;26:4817-4827.

10. Urist MR, Silverman BF, Buring K, Dubuc FL, Rosenberg JM. The bone induction principle. Clin Orthop Relat Res 1967;53:243-283.

11. Barradas AM, Yuan $H$, van Blitterswijk CA, Habibovic P. Osteoinductive biomaterials: Current knowledge of properties, experimental models and biological mechanisms. Eur Cell Mater 2011; 21:407-429; discussion 29.

12. Suárez-González D, Barnhart K, Migneco F, Flanagan C, Hollister SJ, Murphy WL. Controllable mineral coatings on PCL scaffolds as carriers for growth factor release. Biomaterials 2012;33:713721.

13. Jongpaiboonkit L, Franklin-Ford T, Murphy WL. Growth of hydroxyapatite coatings on biodegradable polymer microspheres. ACS Appl Mater Interfaces 2009;1:1504-1511.

14. Kim M, Choe S. BMPs and their clinical potentials. BMB Rep 2011;44:619-634.

15. Herford AS, Cicciu M. Recombinant human bone morphogenetic protein type 2 jaw reconstruction in patients affected by giant cell tumor. J Craniofac Surg 2010;21:1970-1975.

16. Boyne PJ. Application of bone morphogenetic proteins in the treatment of clinical oral and maxillofacial osseous defects. J Bone Joint Surg Am 2001;83-A Suppl 1(Pt 2):S146-150.

17. Wang EA, Rosen V, Cordes $P$, Hewick RM, Kriz MJ, Luxenberg DP, Sibley BS, Wozney JM. Purification and characterization of other distinct bone-inducing factors. Proc Natl Acad Sci USA 1988;85:9484-9488.

18. Herford AS, Boyne PJ, Williams RP. Clinical applications of rhBMP-2 in maxillofacial surgery. J Calif Dent Assoc 2007;35:335341.

19. Wei G, Jin Q, Giannobile WV, Ma PX. The enhancement of osteogenesis by nano-fibrous scaffolds incorporating rhBMP-7 nanospheres. Biomaterials 2007;28:2087-2096.

20. Forriol F, Longo UG, Concejo C, Ripalda P, Maffulli N, Denaro V. Platelet-rich plasma, rhOP-1 (rhBMP-7) and frozen rib allograft for the reconstruction of bony mandibular defects in sheep. A pilot experimental study. Injury 2009;40 Suppl 3:S44-49.

21. Busuttil Naudi K, Ayoub A, McMahon J, Di Silvio L, Lappin D, Hunter KD, Barbenel J. Mandibular reconstruction in the rabbit using beta-tricalcium phosphate (beta-TCP) scaffolding and recombinant bone morphogenetic protein 7 (rhBMP-7)- 
Histological, radiographic and mechanical evaluations. J Craniomaxillofac Surg 2012;40:e461-469.

22. Augello $A, D e$ Bari $C$. The regulation of differentiation in mesenchymal stem cells. Hum Gene Ther 2010;21:1226-1238.

23. Caplan Al, Bruder SP. Mesenchymal stem cells: Building blocks for molecular medicine in the 21st century. Trends Mol Med 2001; 7:259-264.

24. Liu W, Cui L, Cao Y. Bone reconstruction with bone marrow stromal cells. Methods Enzymol 2006;420:362-380.

25. Xiao Y, Mareddy S, Crawford R. Clonal characterization of bone marrow derived stem cells and their application for bone regeneration. Int J Oral Sci 2010;2:127-135.

26. Yuan J, Zhang WJ, Liu G, Wei M, Qi ZL, Liu W, Cui L, Cao YL. Repair of canine mandibular bone defects with bone marrow stromal cells and coral. Tissue Eng Part A 2010;16:1385-1394.

27. Alsberg E, Hill EE, Mooney DJ. Craniofacial tissue engineering. Crit Rev Oral Biol Med 2001;12:64-75.

28. Wu W, Chen X, Mao T, Chen F, Feng X. Bone marrow-derived osteoblasts seeded into porous beta-tricalcium phosphate to repair segmental defect in canine's mandibula. Ulus Travma Acil Cerrahi Derg 2006;12:268-276.

29. Yuan J, Cui L, Zhang WJ, Liu W, Cao Y. Repair of canine mandibular bone defects with bone marrow stromal cells and porous beta-tricalcium phosphate. Biomaterials 2007;28:1005-1013.

30. Xi Q, Bu RF, Liu HC, Mao TQ. Reconstruction of caprine mandibular segmental defect by tissue engineered bone reinforced by titanium reticulum. Chin J Traumatol 2006:9:67-71.

31. Jansen JA, Dhert WJ, van der Waerden JP, von Recum AF. Semiquantitative and qualitative histologic analysis method for the evaluation of implant biocompatibility. J Invest Surg 1994;7:123134.

32. Bagi CM, Berryman E, Moalli MR. Comparative bone anatomy of commonly used laboratory animals: Implications for drug discovery. Comp Med 2011;61:76-85.

33. Boyne PJ. Animal studies of application of rhBMP-2 in maxillofacial reconstruction. Bone 1996;19(1 Suppl):83S-92S.

34. Boyne PJ, Nakamura A, Shabahang S. Evaluation of the longterm effect of function on rhBMP-2 regenerated hemimandibulectomy defects. Br J Oral Maxillofac Surg 1999;37:344-352.

35. Herford AS, Lu M, Buxton AN, Kim J, Henkin J, Boyne PJ, Caruso JM, Rungcharassaeng K, Hong J. Recombinant human bone morphogenetic protein 2 combined with an osteoconductive bulking agent for mandibular continuity defects in nonhuman primates. $J$ Oral Maxillofac Surg 2012;70:703-716.

36. Seto I, Marukawa E, Asahina I. Mandibular reconstruction using a combination graft of rhBMP-2 with bone marrow cells expanded in vitro. Plast Reconstr Surg 2006;117:902-908.
37. Kneser U, Schaefer DJ, Polykandriotis E, Horch RE. Tissue engineering of bone: The reconstructive surgeon's point of view. J Cell Mol Med 2006;10:7-19.

38. Amini AR, Laurencin CT, Nukavarapu SP. Bone tissue engineering: Recent advances and challenges. Crit Rev Biomed Eng 2012; 40:363-408.

39. Vaquette C, Fawzi-Grancher S, Lavalle $\mathrm{P}$, Frochot $\mathrm{C}$, Viriot $\mathrm{ML}$, Muller S, Wang X. In vitro biocompatibility of different polyester membranes. Biomed Mater Eng 2006;16(4 Suppl):S131-136.

40. Seyednejad $H$, Ghassemi AH, van Nostrum CF, Vermonden T, Hennink WE. Functional aliphatic polyesters for biomedical and pharmaceutical applications. J Control Release 2011;152:168-176.

41. Herford AS, Boyne PJ. Reconstruction of mandibular continuity defects with bone morphogenetic protein-2 (rhBMP-2). J Oral Maxillofac Surg 2008;66:616-624.

42. Hussein KA, Zakhary IE, Elawady AR, Emam HA, Sharawy M, Baban B, Akeel S, Al-Shabrawey M, Elsalanty ME. Difference in soft tissue response between immediate and delayed delivery suggests a new mechanism for recombinant human bone morphogenetic protein 2 action in large segmental bone defects. Tissue Eng Part A 2012;18:665-675.

43. Marukawa E, Asahina I, Oda M, Seto I, Alam M, Enomoto S. Functional reconstruction of the non-human primate mandible using recombinant human bone morphogenetic protein-2. Int $\mathrm{J}$ Oral Maxillofac Surg 2002;31:287-295.

44. Seto I, Tachikawa N, Mori M, Hoshino S, Marukawa E, Asahina I, Enomoto S. Restoration of occlusal function using osseointegrated implants in the canine mandible reconstructed by rhBMP2. Clin Oral Implants Res 2002;13:536-541.

45. Seto I, Asahina I, Oda M, Enomoto S. Reconstruction of the primate mandible with a combination graft of recombinant human bone morphogenetic protein-2 and bone marrow. J Oral Maxillofac Surg 2001;59:53-61; discussion 62-63.

46. Zhou Q, Price DD, Callam CS, Woodruff MA, Verne GN. Effects of the $\mathrm{N}$-methyl-D-aspartate receptor on temporal summation of second pain (wind-up) in irritable bowel syndrome. J Pain 2011;12: 297-303.

47. Merkli ATC, Gurny R, Heller J. Biodegradable polymers for the controlled release of ocular drugs. Prog Polym Sci 1998;23:563580.

48. Corden TJ, Jones IA, Rudd CD, Christian P, Downes S, McDougall KE. Physical and biocompatibility properties of poly-epsiloncaprolactone produced using in situ polymerisation: A novel manufacturing technique for long-fibre composite materials. Biomaterials $2000 ; 21: 713-724$ 